\title{
Ocean salinity indices of interannual modes in the tropical Pacific
}

\author{
Jianwei Chi ${ }^{1,2,3,4} \cdot$ Tangdong $\mathrm{Qu}^{4} \cdot$ Yan $\mathrm{Du}^{1,2,3}$ (]) Jifeng $\mathrm{Qi}^{5} \cdot$ Ping Shi ${ }^{1,3}$
}

Received: 26 November 2020 / Accepted: 27 July 2021 / Published online: 7 August 2021

(c) The Author(s) 2021

\begin{abstract}
This study investigates the interannual modes of the tropical Pacific using salinity from observations, ocean reanalysis output and CMIP6 products. Here we propose two indices of sea surface salinity (SSS), a monopole mode and a dipole mode, to identify the El Niño-South Oscillation (ENSO) and its diversity, respectively. The monopole mode is primarily controlled by atmospheric forcing, namely, the enhanced precipitation that induces negative SSS anomalies across nearly the entire tropical Pacific. The dipole mode is mainly forced by oceanic dynamics, with zonal current transporting fresh water from the western fresh pool into the western-central and salty water from the subtropics into the eastern tropical Pacific. Under a global warming condition, an increase in the monopole and dipole mode variance indicates an increase in both the central and eastern Pacific El Niño variability. The increase in central Pacific El Niño variability is largely due to enhanced vertical stratification during global warming in the upper layer, with intensified zonal advection. An eastern Pacific El Niño-like warming pattern contributes to the increase in eastern Pacific El Niño, with enhanced precipitation over the central-eastern tropical Pacific.
\end{abstract}

Keywords Sea surface salinity · El Niño-South Oscillation (ENSO) · Central and eastern Pacific El Niño · Climate change $\cdot$ CMIP6

\section{Introduction}

The El Niño and Southern Oscillation (ENSO) is the most prominent climate mode in the tropical Pacific and significantly influences the world's climate and ecosystem (Ropelewski and Halpert 1987; Vincent et al. 2011; Cai et al. 2014). In recent decades, an unusual pattern of sea surface

Yan Du

duyan@scsio.ac.cn

1 State Key Laboratory of Tropical Oceanography, South China Sea Institute of Oceanology, Chinese Academy of Sciences, 164 West Xingang Road, Guangzhou 510301, China

2 University of Chinese Academy of Sciences, Beijing 100049, China

3 Southern Marine Science and Engineering Guangdong Laboratory (Guangzhou), Guangzhou 511458, China

4 Joint Institute for Regional Earth System Science and Engineering, University of California, Los Angeles, CA 90095, USA

5 CAS Key Laboratory of Ocean Circulation and Waves, Institute of Oceanology, Chinese Academy of Sciences, Qingdao 266071, China temperature (SST) anomalies in 2004 raised the community's interest in the diversity of ENSO (Larkin and Harrison 2005; Ashok et al. 2007). According to the locations of SST anomalies, the warm phase of ENSO, El Niño events, can be classified into two categories: the central and the eastern Pacific El Niño, or CP- and EP-El Niño, respectively (Kao and $\mathrm{Yu}$ 2009). Similarities and differences between the CPand EP-El Niño have received much attention from the scientific community. The obvious 1976-1977 climate shift in the Pacific affected the decadal-scale variability of El Niño through the interannual and decadal oceanic connections between middle latitudes and tropics (Graham 1994; Miller et al. 1994; Trenberth and Hurrell 1994; Zhang et al. 1998; Zhang and Busalacchi 2005). The changes in the characteristics of El Niño, including its intensity and frequency, under global warming (Moon et al. 2015; Cha et al. 2018; Cai et al. 2018) have become an important issue for climate research.

The different types of ENSO result in various robust abnormal states in the ocean and atmosphere in the tropical Pacific. Various indices constructed from different variables have been proposed to classify ENSO and its types. SST associated with air-sea interaction is the best observed oceanic variable. An El Niño (La Niña) event features 
significant positive (negative) SST anomalies in the central and/or eastern equatorial Pacific, accompanied by changes in the ocean-atmosphere coupled system (Rasmusson and Carpenter 1982; Trenberth 1984). To study ENSO diversity, previous studies have introduced a set of SST indices, which emphasize the role of air-sea interaction in ENSO evolution. Kug et al. (2009) and Yeh et al. (2009) suggested the El Niño diversity can be distinguished by contrasting the Niño3 $\left(150-90^{\circ} \mathrm{W}, 5^{\circ} \mathrm{S}-5^{\circ} \mathrm{N}\right)$ and $\mathrm{Niño} 4\left(160^{\circ} \mathrm{E}-150^{\circ} \mathrm{W}, 5^{\circ} \mathrm{S}-5^{\circ} \mathrm{N}\right)$ indices. Ashok et al. (2007) found the main features of two types of El Niño were well captured by the first two SST anomaly EOF modes and defined the El Niño Modoki index (EMI), as SST anomalies averaged in western $\left(125-145^{\circ} \mathrm{E}\right.$, $\left.10^{\circ} \mathrm{S}-20^{\circ} \mathrm{N}\right)$, central $\left(165-140^{\circ} \mathrm{W}, 10^{\circ} \mathrm{S}-10^{\circ} \mathrm{N}\right)$, and eastern $\left(110-70^{\circ} \mathrm{W}, 15^{\circ} \mathrm{S}-5^{\circ} \mathrm{N}\right)$ regions. Kao and $\mathrm{Yu}(2009)$ used a combined regression EOF to remove the signals in the central (Niño4 index) and eastern tropics (Niño1 + 2 index; $\left.90-80^{\circ} \mathrm{W}, 0^{\circ}-10^{\circ} \mathrm{S}\right)$, respectively. The corresponding leading principles (PC1) are introduced to identify the $\mathrm{CP}$ - and EP-El Niño. Furthermore, Takahashi et al. (2011) proposed an E-index and $\mathrm{C}$-index by rotating the first two PCs $45^{\circ}$ clockwise, which indicates the evolution of EP- and CP-El Niño, respectively. From the perspective of the ocean, an index based on the warm water volume is also introduced (Bosc et al. 2009), representing the modulation of equatorial Rossby waves linked with the recharge-discharge oscillator theory (Jin 1997). Besides, variations of the thermocline have been suggested as important features of different ENSO phases (Yu et al. 2011). From the view of the atmosphere, the modulation of general circulation associated with ENSO is well represented by the difference in sea level pressure (SLP) between the western and eastern tropical Pacific (Ropelewski and Jones 1987; Ropelewski and Halpert 1987). Different remote climate impacts on ENSO diversity in North America and North Pacific are indicated by an outgoing longwave radiation index (Chiodi and Harrison 2013).

Investigations from different perspectives provide a comprehensive understanding of ENSO. Water circulation is one of the fundamental components of the ocean-atmosphere coupled system (Du et al. 2019). Its variability can redistribute the heat and freshwater in the upper ocean of the tropical Pacific. On an interannual time scale, water circulation is tightly connected with ENSO. During the development of an El Niño event, anomalous eastward currents warm and freshen the central equatorial Pacific accompanied by eastward propagating downwelling Kelvin waves (Picaut et al. 1997). On the other hand, the active convection due to the positive SST anomaly provides more rainfall that further freshens the mixed layer in the central and eastern equatorial Pacific. Ocean salinity, which can well characterize the fresh water circulation, has been used for ENSO study. Modeling experiments and recent observations suggested that ocean salinity anomaly plays an active role in ENSO evolutions
(Zhu et al. 2014; Zhi et al. 2019a, b). A sharp sea surface salinity (SSS) front (e.g., the 34.8 psu isohaline, the maximum dSSS/dx gradient) separates the freshwater pool in the western Pacific from the salty waters in the central Pacific (Picaut et al. 2001) and its zonal migration along the equator can well distinguish ENSO events (Delcroix and Picaut 1998a, b). Different characteristics of SSS in the tropical Pacific have been used to identify types of El Niño. Singh et al. (2011) found that the west fresh pool moves further east during EP-El Niño than CP-El Niño. Based on this discrepancy in the western Pacific, they distinguished different El Niño types by a SSS El Niño index, defined as the normalized SSS anomaly (SSSA) difference between two adjacent equatorial regions $\left(150^{\circ}-170^{\circ} \mathrm{E}, 2^{\circ} \mathrm{S}-2^{\circ} \mathrm{N} ; 170^{\circ} \mathrm{E}-170^{\circ} \mathrm{W}\right.$, $\left.2^{\circ} \mathrm{S}-2^{\circ} \mathrm{N}\right)$. Besides the western Pacific, Qu and Yu (2014) found that SSS variability in the southeastern tropical Pacific $\left(150-90^{\circ} \mathrm{W}, 0^{\circ}-10^{\circ} \mathrm{S}\right)$ is crucial to identify different types of El Niño and proposed a southeastern Pacific SSS index (SEPSI). A recent study using observations and reanalysis products indicated the distinct SSS signatures between two types of El Niño are confined to the west Pacific fresh pool and Niño3.4 region $\left(170^{\circ}-120^{\circ} \mathrm{W}, 5 \mathrm{~S}^{\circ}-5^{\circ} \mathrm{N}\right)$ (Qi et al. 2019). Modeling studies indicate that freshwater flux and ocean salinity play a role in SST variability and ENSO evolution through influencing surface stratification, equatorial thermocline and entrainment of subsurface water (Murtugudde and Busalacchi 1998; Yang et al. 1999; Maes et al. 2002; Zhang and Busalacchi 2009; Zhang and Busalacchi 2009; Qu et al. 2014; Zheng et al. 2014). The barrier layer in the western and central tropical Pacific, for example, is critical to the onset and development of El Niño by insulating cold and salty water from the subsurface (Maes et al. 2002; Qu et al. 2014).

The hydrological cycle variability associated with El Niño event causes worldwide severe effects on society and the environment, such as the flooding in the southwest USA (Ropelewski and Jones 1987) and droughts in the western Pacific counties (McPhaden et al. 2006). The seawater salinity is an important indicator for the hydrological cycle and its interannual variability is tightly linked to ENSO. Therefore, determining the hydrological features for the two types of El Niño and how its variability responds to greenhouse warming is one of the most important issues in climate science. In this study, we propose two SSS indices to explain the similarities and differences of the hydrological cycle between the CP- and EP-El Niño using results from an ocean state estimate of the consortium for Estimating the Circulation and Climate of the Ocean (ECCO) combined with the TAO/TRITON mooring observations. Furthermore, the Coupled Model Intercomparison Project phase 6 (CMIP6), which provided a standard experimental protocol and an infrastructure, gives a perspective to investigate the responses of the hydrological cycle to greenhouse warming. 
The rest of the paper is organized as follows. Section 2 gives a brief introduction to the data and methods used in this study. The new SSS indices are presented in Sect. 3, followed by the physical mechanism analysis associated with these indices in Sect. 4. The interannual variability of the tropical Pacific under a global warming condition is investigated using these indices in Sect. 5. Finally, Sect. 5 presents a summary and discussion.

\section{Data and methods}

\subsection{Data}

The ECCO is based on the Massachusetts Institute of Technology general circulation model (Marshall et al. 1997) and extends from $80^{\circ} \mathrm{S}$ to $80^{\circ} \mathrm{N}$. Different from the $1^{\circ}$ zonal resolution globally, the meridional spacing is $0.3^{\circ}$ within $10^{\circ}$ of the equator and gradually increases to $1^{\circ}$ beyond $20^{\circ}$. Vertical resolution is $10 \mathrm{~m}$ within the upper layer $(150 \mathrm{~m})$ and increases to $400 \mathrm{~m}$ near the bottom of the ocean. Initially, at rest with climatological temperature and salinity from the World Ocean Atlas 1998 (WOA98), this model is spun up for 10 years by climatological seasonal wind stress along with air-sea flux of the Comprehensive Ocean-Atmosphere Data Set (COADS). Flowing the spin up, the model is forced by the National Centers for Environmental Prediction (NCEP) reanalysis products (Kalnay et al. 1996). The Redi isoneutral mixing scheme (Redi 1982) and the Gent and McWilliams parameterization (Gent and McWilliams 1990) are employed to parameterize mesoscale eddy fluxes. For the mixing processes in the mixed layer, the K-Profile Parameterization (KPP) vertical mixing scheme is employed (Large et al. 1994). The run we chose is the ECCO near real-time state estimate (ECCO-KFS dr080) distributed by Jet Propulsion Laboratory (JPL) for the period 1993-2016. This product assimilates sea level anomalies from satellites (TOPEX/Poseidon, Jason-1, and Jason-2) and temperature profiles from in-situ measurements (e.g., Argo, XBTs, and CTDs), by a partitioned Kalman filter and Rauch-Tung-Striebel (RTS) smoother (Fukumori 2002). Compared with the only Kalman filter run, the dr080 assimilation is physically consistent, well suited for the salinity budget analyses. This output is available from https://ecco.jpl.nasa.gov/. Previous studies suggested that the ocean's general circulation and water properties simulated by ECCO are fairly consistent with observations (Chi et al. 2019; Gao et al. 2014; Lee and Fukumori 2003; Qu et al. 2011; Wang et al. 2004).

We also apply salinity observations from a gridded Argo product, the tropical moored buoy array, and EN4 objective analyses. This Argo product is constructed by the International Pacific Research Center (IPRC) and provides monthly salinity and temperature from 2005 to present, with $1^{\circ}$ horizontal resolution, which is available from http://apdrc. soest.hawaii.edu/dods/public_data/Argo_Products. The Tropical Atmosphere Ocean/Triangle Trans-Ocean Buoy Network (TAO/TRITON) consists of nearly 70 moorings spread across the tropical Pacific, which was an important part of the Tropical Ocean Global Atmosphere (TOGA) program (McPhaden et al. 2010), which can be obtained from https://www.pmel.noaa.gov/tao/drupal/disdel/. EN4.2.1 is the latest version of the "EN" series data sets from Met Office Hadley Centre and covers the period from 1900 to present (Good et al. 2013), which is available from http:// hadobs.metoffice.com/en4/. These EN4 objective analyses ingested data from all types of ocean profiling instruments that provide temperature and salinity information. Besides, we used monthly sea surface wind from the National Centers for Environmental Prediction of the Department of Energy Reanalysis 2 (NCEP-DOE 2, https://psl.noaa.gov/data/gridd ed/data.ncep.reanalysis $2 . h t m l)$ and monthly precipitation from the Global Precipitation Climatology Project version 2.3 (GPCP2.3, http://eagle1.umd.edu/GPCP_CDR/Month ly_Data/). We also applied the monthly sea surface current from Ocean Surface Current Analysis Real-time (OSCAR) provided by NOAA (http://www.oscar.noaa.gov).

To identify the variability under global warming, we also used 10 coupled global climate model outputs from CMIP6, including the historical simulations and the Scenario Model Intercomparison Project (ScenarioMIP) experiments, which are available from https://esgf-node.llnl.gov/. The historical simulations we selected are forced with historical anthropogenic and natural forcing for the period 1850-2014. Extending these historical simulations, the corresponding ScenarioMIP experiments use the future greenhouse gas concentrations under the Shared Socioeconomic Pathway 2-4.5 (SSP2-4.5) (2015-2100). All the model outputs are de-trended before the analysis.

\subsection{Methods}

We conduct mixed layer salinity budget analysis and attribute the mixed layer salinity tendency to surface forcing (precipitation, evaporation) and oceanic dynamics (advection, entrainment, and mixing) (Kim et al. 2006; Qu et al. 2011; Gao et al. 2014; Chi et al. 2019). The mixed-layer salinity budget can be expressed as

$$
\frac{\partial[S]}{\partial t}=\frac{(E-P)}{h}[S]-[\nabla \cdot(u S, v S)]_{m l}+[\text { mixing }]_{m l}+\text { subsurface }
$$

subsurface $=-\frac{1}{h} \Delta S \frac{\partial h}{\partial t}-[\nabla \cdot(u S, v S)]_{\text {induct }}-\left[\nabla_{z}(w S)\right]+[\text { mixing }]_{z}$

where the square bracket represents the depth average within the mixed layer. The mixed layer depth (MLD), $h$, is defined 
as the depth where the density increases from the surface value due to a $0.2{ }^{\circ} \mathrm{C}$ temperature decrease. [S] and $\Delta S$ denote the mixed layer salinity and the salinity jump across the base of the mixed layer; $\mathrm{u}$ and $\mathrm{v}$ are zonal and meridional components of velocity; the subscript $\mathrm{H}$ and $\mathrm{Z}$ denote horizontal and vertical components of a variable. The MLS tendency, $\frac{\partial[S]}{\partial t}$, attributes to three parts in this study: the surface forcing, horizontal advection, and subsurface processes. The surface forcing, the first term on the right-hand side of Eq. (1), represents the effect of evaporation minus precipitation (E-P). The horizontal mixing is at least one order smaller than horizontal advection over the tropical Pacific in the mode result (not shown), so we combine these two terms and refer to the new term as "horizontal advection" for simplicity of discussion (Gao et al. 2014). The "subsurface" processes in Eq. (2) consist of the entrainment (the first two terms), vertical advection (the third term), and the subsurface component of mixing (the last term). The $[\text { mixing }]_{Z}$ consists of the vertical turbulent diffusion at the base of the mixed layer, the GM mixing (Gent and McWilliams 1990), and the KPP nonlocal component within the mixed layer (Large et al. 1994). All terms of Eqs. (1) and (2) are computed at the model's integration time step and archived as day averages.

\section{New SSS indices}

The predominant features of mean SSS distribution in the Pacific are two maxima in the southern and northern subtropical gyres and two fresh pools in the northwestern and northeastern tropics. The SSS in the western tropical Pacific shows a significant interannual variability with its standard deviation exceeding $0.5 \mathrm{psu}$. This interannual variability of SSS is closely related to ENSO. Its correlation with the Niño-3.4 index reaches -0.70 (satisfy $95 \%$ confidence level). On the one hand, the SSS gradient near the westerncentral equatorial is intense (1.0 psu in $1^{\circ}$ longitude) (Delcroix and McPhaden 2002; Maes 2008; Rodier et al. 2000), which provides a background for the strong salinity advection when the anomalous zonal currents develop. On the other hand, the convection and precipitation are intense in the western tropical Pacific. The variance of the convection will result in a conspicuous SSS variability.

Takahashi et al. (2011) indicated the SST El Niño indices (Niño3, Niño4, EMI, etc.) could be well estimated by the linear combination of the first two PCs with coefficients of determination $\left(\mathrm{R}^{2}\right)$ exceeding $95 \%$. They proposed the $45^{\circ}$ rotation of the $\mathrm{PC} 1$ and $\mathrm{PC} 2$ of SST EOF as C-index and E-index, which account for extreme warm events in the eastern and cold/moderate warm events in the central equatorial Pacific, respectively. Since SSS variability shows a high correlation with ENSO, whether there are reasonable indices to identify ENSO and its diversity raises our interest. There were already several SSS indices. The first index, termed Niño-S34.8, is defined as the longitudinal location of the 34.8 psu isohaline along the equator, representing the SSS front near the eastern edge of the western Pacific warm pool (Delcroix 1998; Qu and Yu 2014). Previous studies based on Aquarius and Argo observations have confirmed the correspondence between the SSS front and ENSO. Based on a monthly SSS product derived from data originating from Voluntary Observing Ships, TAO/TRITON moorings, CTD, and Argo profilers, Singh et al. (2011) suggested two indices, SSS-ENSO and SSS-El Niño, to identify the phases of ENSO and types of El Niño. The SSS-ENSO is defined as the difference between the normalized SSSA averaged in the South Pacific Convergence Zone (SPCZ; $160^{\circ} \mathrm{E}-160^{\circ} \mathrm{W}$, $\left.25^{\circ}-10^{\circ} \mathrm{S}\right)$ and the central equatorial Pacific $\left(150^{\circ} \mathrm{E}-170^{\circ} \mathrm{W}\right.$, $2^{\circ} \mathrm{S}-2^{\circ} \mathrm{N}$ ). Recently, Qu and $\mathrm{Yu}$ (2014) proposed the SEPSI, which emphasizes the importance of a large-scale SSS gradient between the central and eastern equatorial Pacific. The definitions of SSS-El Niño and SEPSI have been introduced in the Induction Section.

The empirical orthogonal function (EOF) analysis has been widely applied to studying the leading patterns of interannual variability (Ashok et al. 2007; Kao and Yu 2009). A simple test of significance (North et al. 1982) is applied to the eigenvalues, which shows the first two EOFs from ECCO simulation can be distinguished in a statistically significant way. The EOF1 of SSSA is characterized by negative values in the central and western equatorial Pacific, which accounts for $48 \%$ of the variance on interannual time scales (Fig. 1). As for the EOF2 pattern (23\%), negative SSSAs cover the central and eastern equatorial Pacific. Based on the spatial differences between the two patterns, we estimate the EOF time series (principal components, PCs) by SSSA in three areas (red boxes in Fig. 1b: A $\left[8^{\circ} \mathrm{S}-8^{\circ} \mathrm{N}, 140^{\circ}-160^{\circ} \mathrm{E}\right]$, B $\left.\left[8^{\circ} \mathrm{S}-8^{\circ} \mathrm{N}, 170^{\circ} \mathrm{E}-160^{\circ} \mathrm{W}\right], \mathrm{C}\left[8^{\circ} \mathrm{S}-8^{\circ} \mathrm{N}, 150^{\circ}-110^{\circ} \mathrm{W}\right]\right)$ (Fig. 1b):

$$
\begin{aligned}
& \mathrm{PC}^{*}=\operatorname{SSSA}_{(\mathrm{C})}-\operatorname{SSSA}_{(\mathrm{A}+\mathrm{B})}=\operatorname{SSSA}_{(\mathrm{C}-\mathrm{A}-\mathrm{B})} \\
& \mathrm{PC}^{*}=\operatorname{SSSA}_{(\mathrm{A})}-\operatorname{SSSA}_{(\mathrm{B}+\mathrm{C})}=\operatorname{SSSA}_{(\mathrm{A}-\mathrm{B}-\mathrm{C})}
\end{aligned}
$$

where $*$ denotes the estimates. The normalized difference $(\mathrm{C}-(\mathrm{A}+\mathrm{B}))$ between the normalized average SSSA in the third region (the eastern tropical Pacific) and the sum of the normalized average SSSA in the first two regions (the western and central tropical Pacific) resembles PC1 in almost all the details with their correlation reaching 0.95 (satisfy $99 \%$ confidence level). The same happens to the PC2 $(r=0.92)$, which is well represented by the normalized difference (A $-(B+C))$ between the normalized average SSSA in the first region (the western tropical Pacific) and the sum of the normalized average SSSA in the latter two regions (the central 
Fig. 1 Spatial structures and time functions for sea surface salinity anomaly (SSSA) EOFs in the tropical Pacific from ECCO product. The red box $\mathbf{a}, \mathbf{b}$, and $\mathbf{c}$ in $\mathbf{b})$ represent the region $\left[140^{\circ}-160^{\circ} \mathrm{E}, 8^{\circ} \mathrm{S}-8^{\circ} \mathrm{N}\right]$, $\left[170^{\circ} \mathrm{E}-160^{\circ} \mathrm{W}, 8^{\circ} \mathrm{S}-8^{\circ} \mathrm{N}\right]$, and $\left[150^{\circ}-110^{\circ} \mathrm{W}, 8^{\circ} \mathrm{S}-8^{\circ} \mathrm{N}\right]$, respectively. The gray (black) diamonds in b) denote the TAO/TRITON moorings which are in (out) these red boxes. The values in the titles denote explained variances. c The dashed lines are results estimated by SSSA from areas $\mathbf{a}, \mathbf{b}$, and $\mathbf{c}$. The units are $1.0 \mathrm{psu}$ (a) SSS EOF1 (ECCO 1993-2016; 48\%)

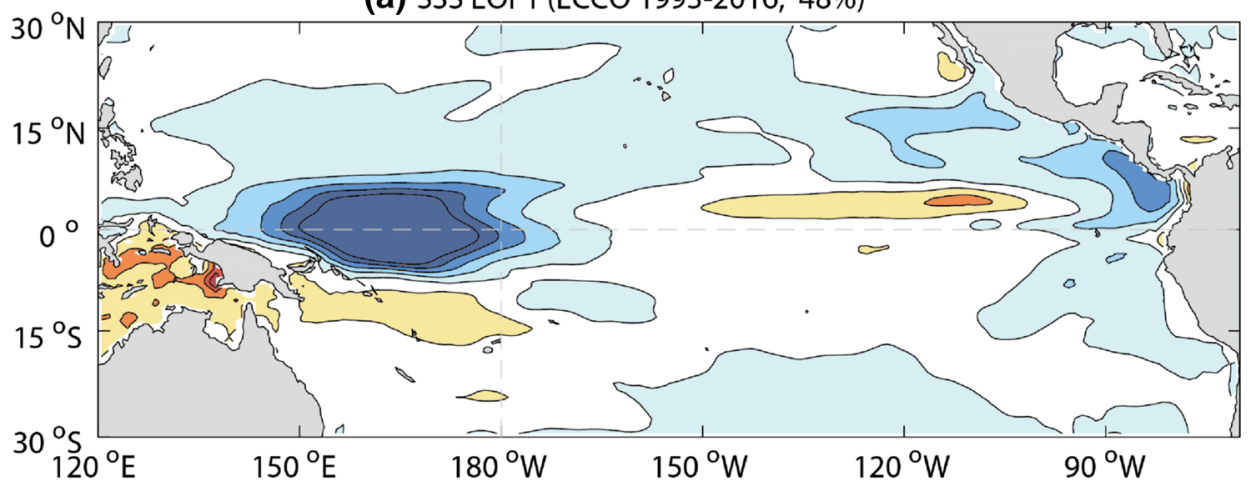

(b) SSS EOF2 (ECCO 1993-2016; 23\%)

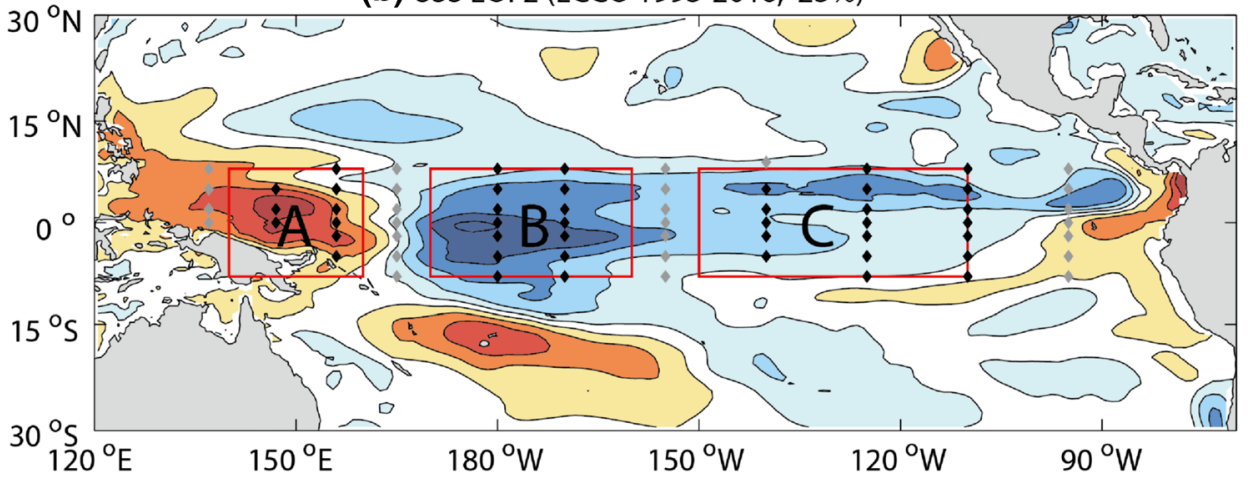

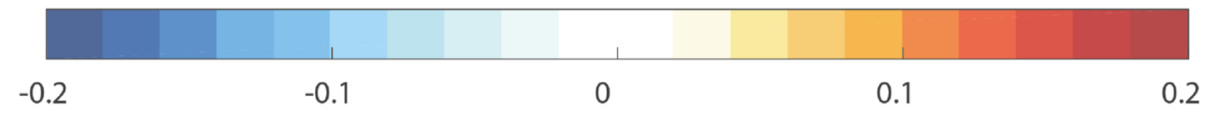

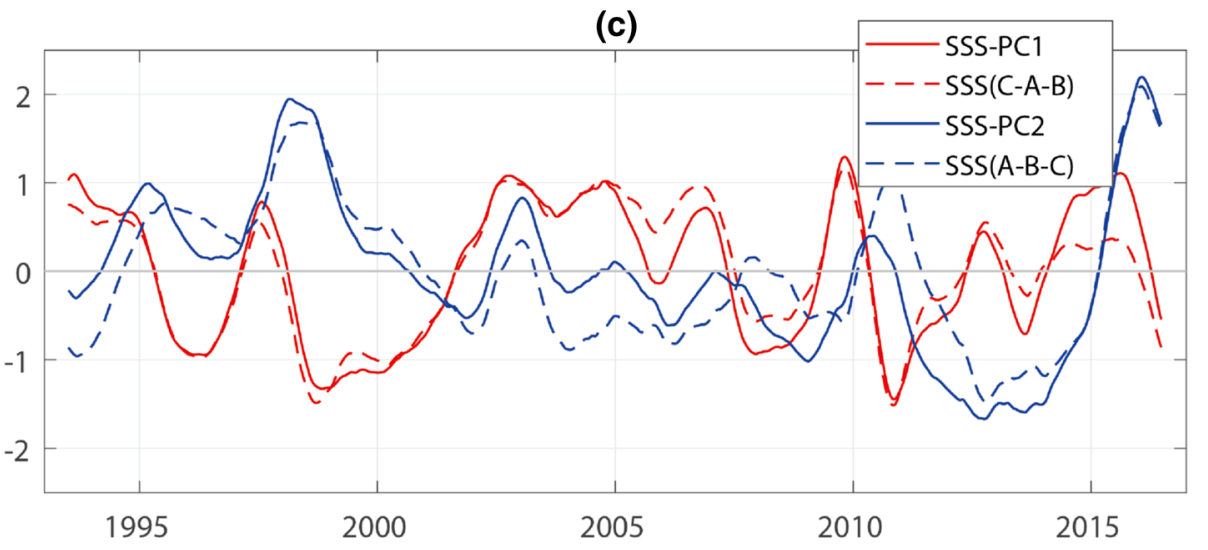

and eastern tropical Pacific). These correlation coefficients are very high, so we will not make an explicit distinction between the actual series and their estimates.

Using multiple regression, we linearly combined the first two SSS PCs to estimate the SSS El Niño indices. Similar to SST (Takahashi et al. 2011), the first two SSS PCs could well linearly represent all SSS indices. For example, SSS-ENSO is estimated as the sum of 0.75 times $\mathrm{PC} 1$ and 0.26 times $\mathrm{PC} 2$, with $\mathrm{R}^{2}$ reaching $93 \%$. Figure 2 showed the scatters of December-February mean SSSA $\mathrm{PC} 1$ and PC2. According to the regression EOF method of SST anomaly (Kao and Yu 2009), we denoted the years of neutral, La Niña, CP- and EP-El Niño with the gray, blue, purple, and red cycle in Fig. 2. The results showed that the $45^{\circ}$ rotation axes of PC1 and PC2 divided most $(21 / 23)$ four different scatters into four quadrants. These rotation axes are labeled as 'MSI' index and 'DSI', corresponding to a Monopole SSS Mode and a Dipole SSS Mode, respectively. Besides, the first two PCs can be well estimated by SSSA in regions (A, B, C) (Eq. 3 and Eq. 4), so the corresponding indices are defined as: 


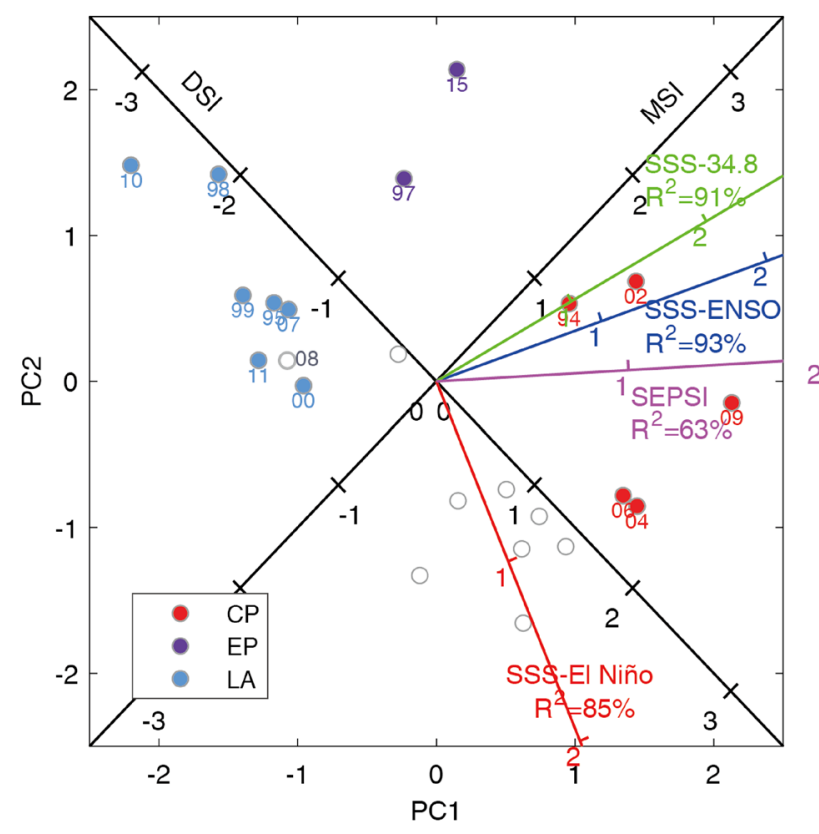

Fig. 2 Scatters of the SSSA EOF PC1 and PC2 December-February averaged for the period 1993-2016 from ECCO product. The axes correspond to different multiple-regression estimates of SSS Niño indices (variance explained indicated). The rotation $45^{\circ}$ axes of PC1 and PC2 denote the MSI and DSI indices. According to the method of (Kao and Yu 2009), central Pacific (CP-) El Niño, eastern Pacific (EP-) El Niño, and La Niña events are classified and represented as the purple, red, and purple circles

$$
\begin{aligned}
& \mathrm{MSI}=(\mathrm{PC} 1+\mathrm{PC} 2) / \sqrt{2}=-\sqrt{2} \mathrm{SSSA}(\mathrm{B}) \\
& \mathrm{DSI}=(\mathrm{PC} 1-\mathrm{PC} 2) / \sqrt{2}=\sqrt{2} \mathrm{SSSA}(\mathrm{C}-\mathrm{A})
\end{aligned}
$$

The MSI and DSI can be estimated by the normalized SSSA in the central tropical Pacific $\left(\mathrm{SSSA}_{(\mathrm{B})}\right)$ and the normalized difference between the normalized SSSA averaged in the eastern and western tropical Pacific $\left(\mathrm{SSSA}_{(\mathrm{C}-\mathrm{A})}\right)$, respectively.

The SSS patterns associated with the MSI and DSI indices show a monopole and a dipole pattern over the tropical Pacific (Fig. 3a and 3b), defined as:

Monopole mode $=(\mathrm{EOF} 1+\mathrm{EOF} 2) / \sqrt{2}$

Dipole mode $=(\mathrm{EOF} 1-\mathrm{EOF} 2) / \sqrt{2}$

The monopole mode shows a unique pole in the western-central Pacific, while the dipole mode consists of a pair of poles with opposite signs between the western and central-eastern equatorial Pacific.
The time series of the MSI and DSI indices show significant interannual variability, which is distinct for two types of El Niño (Fig. 3c). The CP-El Niño features the positive values of MSI and DSI indices, which denote negative and positive SSSA centers is located in the western and central-eastern equatorial Pacific, respectively. The EP-El Niño events show an extreme positive MSI and a negative DSI along with the negative SSSA covering the central-eastern equatorial Pacific. Now that the MSI and DSI can well classify the ENSO phases and El Niño types, we define the CP-El Niño, EP-El Niño, and La Niña events as [MSI+DSI $>1$ s.d., MSI $>0$, DSI $>0$ ], [MSI - DSI $>1$ s.d., MSI $>0$, DSI $<0$ ], $[\mathrm{MSI}+\mathrm{DSI}<--1$ s.d., MSI $<0, \mathrm{DSI}<0]$, respectively. Figure $3 \mathrm{~d}$ shows the scatters of the SSSA averaged between December and the following February from the ECCO product and TAO/TRITON observation. According to the event definitions in terms of MSI and DSI indices, there are four regimes: light-red, light-purple, light-blue, and white areas corresponding to CP-El Niño event, EP-El Niño event, La Niña event, and normal year, respectively.

Based on the classification method of MSI and DSI indices, all the ENSO events for the period 1993-2016 are identified from ECCO simulation, which includes 5 CP-El Niño (1994/95, 2002/03, 2004/05, 2006/07, 2009/10), 2 EP-El Niño (1997/1998, 2015/2016), and 8 La Niña events (1995/96, 1998/99, 1999/00, 2000/01, 2007/08, 2008/09, 2010/11, 2011/12) (Fig. 3d \& Table 1). These results are consistent with those from TAO/TRITON SSS moorings, which indicates good reliability of this classification method (Fig. 3e). We also apply other indices estimated with SST and SSS to check these new indices (Table 1). The former emphasizes the role of air-sea interaction in the tropical Pacific, while the latter focuses on the fresh water transport. Results classified by SST and SSS indices show a reasonable agreement. It is worth noting that the SSS indices identify more La Niña events (1996/97, 2005/06, 2008/09, and 2013/14) than the SST indices. During 2008 boreal winter, the central-eastern equatorial Pacific was colder than a normal year but it was too weak to identify it as a $\mathrm{La}$ Niña event, while the SSS in the western-central equatorial Pacific noticeably increased accompanying with decreasing precipitation (not shown). In defining SSS-ENSO and SSSEl Niño indices, Singh et al. (2011) emphasized the importance of SSS gradient between the central-western Pacific and SPCZ and SSS gradient between the central and western Pacific, respectively. Qu and $\mathrm{Yu}$ (2014) focused on SSSA in the southern tropical Pacific and defined the SEPSI. The present study highlights fresh water transport in the tropical Pacific. These indices emphasize different aspects of salinity anomalies during CP- and EP-El Niño events and require further investigations to understand their differences.

The lead/lag relationships of the first two SSSA PCs, MSI, DSI and other ENSO indices are estimated in Table 2. 

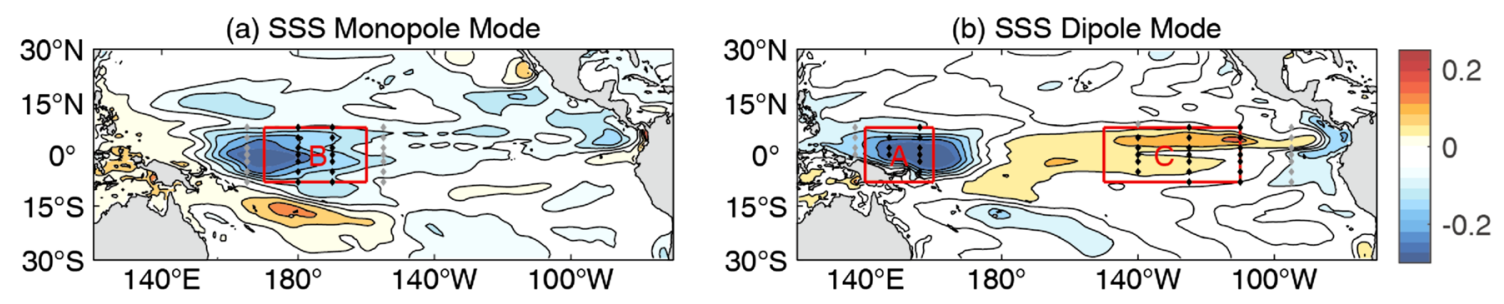

(c) MSI \& DSI

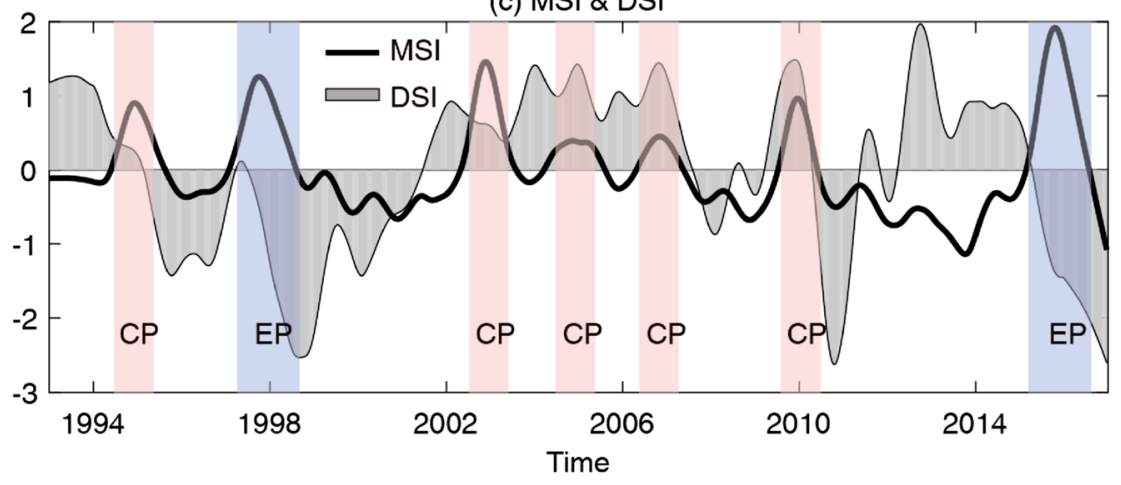

(d) ECCO

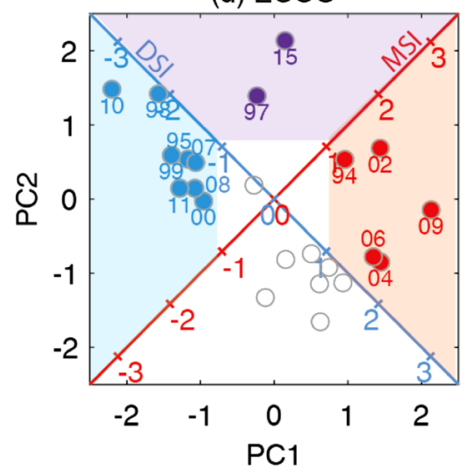

(e) TAO/TRITON
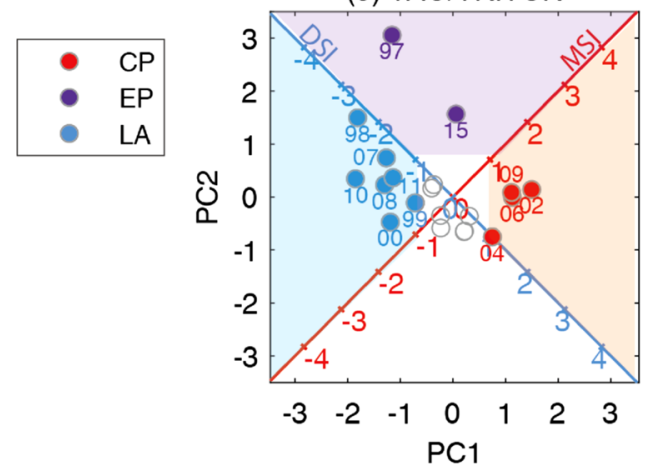

Fig. 3 Spatial structure and variability of the tropical Pacific sea surface salinity (SSS) monopole and dipole modes. a SSS monopole mode; b SSS dipole mode. c Time series of MSI (black thick line) and DSI (gray bar) indices. Scatters of December-February (DJF) mean SSSA EOF PC1 and PC2 from (d) ECCO and (e) TAO/TRITON. The PCs are estimated by SSSA in areas A, B, and C. The red, purple, and blue circles denote the years of CP-El Niño, EP-El Niño,

The PC1 shows good relationships with the other indices (Niño3.4, Niño4, EMI, SSS-ENSO, and SSS-El Niño). As for the PC2, only the correlations with EMI and SSSEl Niño pass the reliability test. The MSI lags Niño3.4 by about 2 months, with a maximum correlation of 0.74 . It takes about 2 months for SSS to respond in the coupled system of the central equatorial Pacific, which suggests a tight link between the monopole mode and surface forcing. On the other hand, the DSI leads EMI by about 6 months, with a maximum correlation of 0.64 . This may be attributed to two processes. One lies in the fact that the DSI emphasizes the variability in the western Pacific and it takes about 3 months for this variability to reach the eastern Pacific, according to and La Niña. The light-red, light-purple, light-blue, and white areas correspond to classification regimes of CP-El Niño, EP-El Niño, La Niña events, and normal years, respectively. The red and blue diagonal axes represent MSI and DSI according to their relationship with PCs. The seasonal cycles are removed. The results in $(\mathbf{c}, \mathbf{d}, \mathbf{e})$ are standardized. The units in $(\mathbf{a}, \mathbf{b})$ are 1 psu

the delayed oscillator theory (Suarez and Schopf 1988). The other is related to the zonal water transport that leads sea level by about 3 months (Zhang and Clarke 2017). Besides, the MSI and DSI indices show significant seasonal phase locks (not shown). MSI composite indicates that the monopole mode peaks in December during an El Niño event development year but reaches its nadir in February of a $\mathrm{La}$ Niña mature year. DSI remains positive and peaks in September of a CP-El Niño year, but it becomes negative and hits the bottom in September of an EP-El Niño recession year.

The evolution of the monopole and dipole modes varies among different types of events. Figure 4 displays the 
Table 1 Years of EP-El Niño, CP-El Niño, and La Niña events as defined by the various criteria

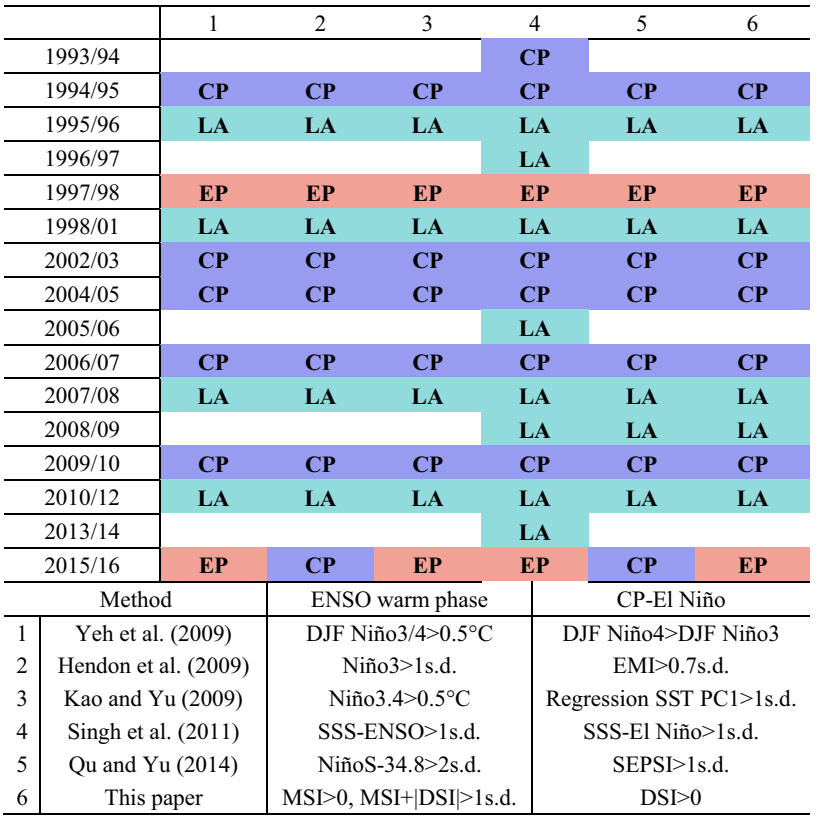

The resulta are from ECCO product. The EP-El Niño, CP-El Niño, and La Niña events are denoted in red, blue, and turquoise. The references and corresponding criteria are listed at the bottom table

evolution of MSI and DSI indices from May to the following February during CP-El Niño, EP-El Niño, La Niña, and normal years. The scatters mainly stay at one quadrant of MSI and DSI axes. MSI peaks in October to December of the El Niño development year. DSI remains positive and stable during the development year of a CP-El Niño, but it becomes negative and hits the bottom in September of the recession year of an EP-El Niño. The scatters of SSSA during the La Niña and normal years fall in the third and fourth quadrant of the rotating axes, respectively.

\section{Physical mechanisms responsible for SSS climate modes}

To better understand the atmospheric and oceanic processes associated with the SSS monopole mode and dipole mode, we regress precipitation, sea surface wind, and sea surface current to the MSI and DSI, respectively (Fig. 5). The regressed-precipitation is highly associated with the monopole mode, featured by much more precipitation $(3.8 \mathrm{~mm} /$ day; $178^{\circ} \mathrm{W}, 4^{\circ} \mathrm{S}$ ) over the central to eastern tropical Pacific and less precipitation $\left(-2.2 \mathrm{~mm} /\right.$ day; $\left.134^{\circ} \mathrm{E}, 4^{\circ} \mathrm{N}\right)$ in the western Pacific. Warm SST anomalies are conducive to active convection and anomalous sea surface wind convergence along the equator (Fig. 5a). The ascending branch of the Walker circulation moves eastward (not shown) with strong precipitation covering the central and eastern equatorial Pacific (Fig. 5a). The descending branch of the Walker circulation results in a positive SSS tendency near the western Pacific fresh pool. The impact of sea surface current associated with the monopole mode focuses on the western and central-eastern equatorial Pacific, where the eastward fresh water transport is limited at the west of $140^{\circ} \mathrm{W}$. The westerly wind bursts (Fig. 5a) lead to anomalous eastward current in the upper ocean (Fig. 5c). The anomalous eastward current carries warm and fresh water from the western to the central-eastern (near $140^{\circ} \mathrm{W}$ ) equatorial Pacific. These suggest the precipitation may play a dominant role in the monopole mode evolution, especially in the eastern tropical Pacific.

Different from the monopole mode, zonal advection dominates the dipole mode. DSI-regressed current shows that the eastward anomalies cover the entire equatorial Pacific (Fig. 5d). Besides current, the distribution of SSS is another factor for salinity advection. A high-salinity ridge, emanating from the southern subtropics is located near the dateline, which separates the low salinity water in the western

Table 2 Lead/lag relationship between PC1, PC2, MSI, and DSI indices with other indices

\begin{tabular}{c|ccccccc}
\hline $\begin{array}{c}\text { Cor } \\
(\mathrm{Lead} / \mathrm{Lag})\end{array}$ & Niño3.4 & Niño3 & Niño4 & EMI & SEPSI & SSS-ENSO & $\begin{array}{c}\text { SSS-El } \\
\text { Niño }\end{array}$ \\
\hline PC1 & $\mathbf{0 . 5 8 ( 2 )}$ & $0.35(4)$ & $\mathbf{0 . 6 7 ( 4 )}$ & $\mathbf{0 . 7 8 ( 2 )}$ & $0.46(-2)$ & $\mathbf{0 . 7 8 ( 1 )}$ & $\mathbf{0 . 6 8 ( - 2 )}$ \\
PC2 & $0.46(-11)$ & $-0.43(-11)$ & $-0.38(-11)$ & $\mathbf{0 . 5 5 ( - 1 1 )}$ & $-0.22(2)$ & $-0.41(11)$ & $\mathbf{- 0 . 7 1 ( 1 )}$ \\
MSI & $\mathbf{0 . 7 4 ( - 2 )}$ & $\mathbf{0 . 6 0 ( 1 )}$ & $\mathbf{0 . 6 3 ( - 1 )}$ & $\mathbf{0 . 6 8 ( - 3 )}$ & $0.32(-4)$ & $\mathbf{0 . 7 0 ( - 2 )}$ & $-0.30(7)$ \\
& & & & & & & \\
DSI & $0.37(6)$ & $-0.37(-11)$ & $0.49(7)$ & $\mathbf{0 . 6 4 ( 6 )}$ & $0.35(-1)$ & $\mathbf{0 . 5 5 ( 3 )}$ & $\mathbf{0 . 7 6 ( - 1 )}$ \\
\hline
\end{tabular}

The colorful numbers denote the correlations exceed a $95 \%$ confidence level. The positive (negative) numbers in the brackets denote the lead (lag) time (month) of PC1/PC2/MSI/DSI 
Fig. 4 Evolution of MSI and DSI indices from May to the following February for the years of (a) CP-El Niño, (b) EP-El Niño, (c) La Niña, and (d) normal. The numbers along tracks denote the month. The results are from ECCO (a) CP-EI Niño

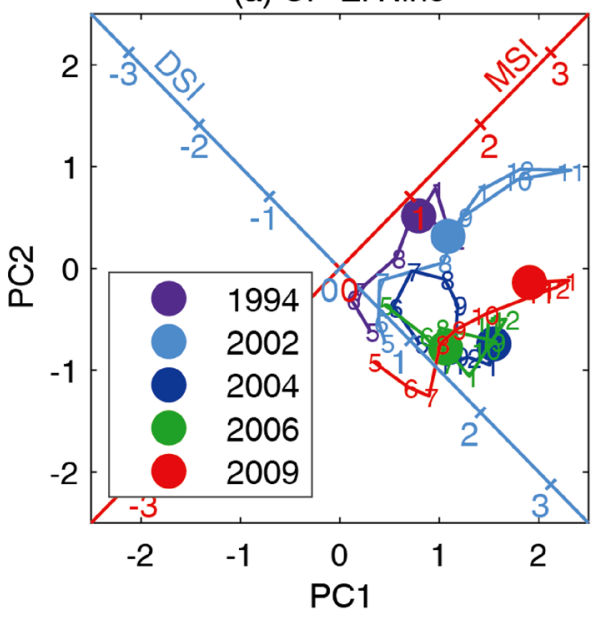

(c) La Niña

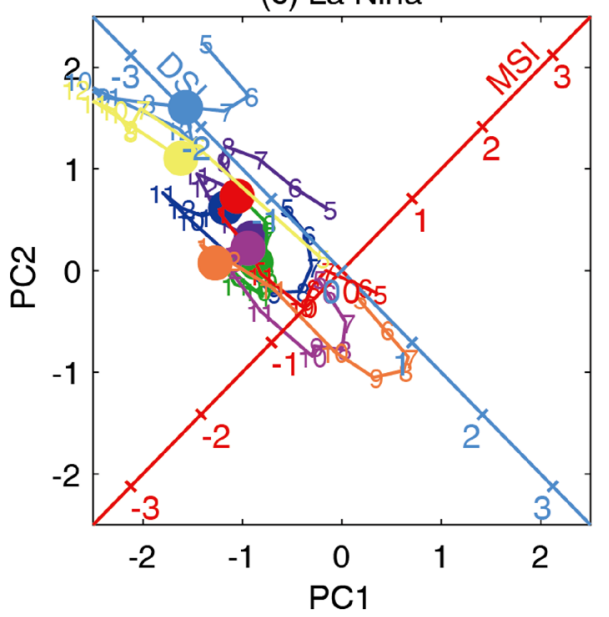

(b) EP-EI \$Niñ

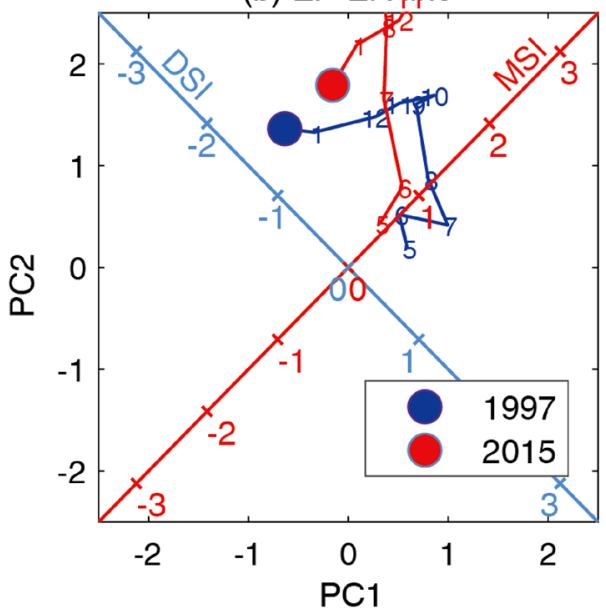

(d) Normal

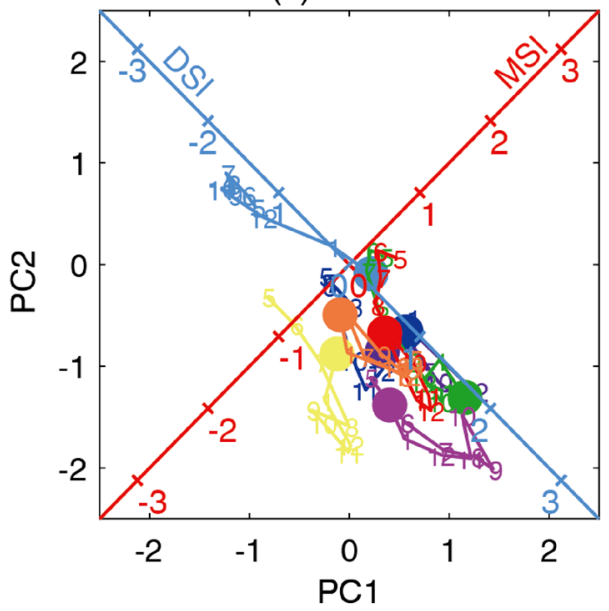

equatorial Pacific from that in the east. Zonal currents are the main components for the upper layer current system in the tropical Pacific, so this high-salinity ridge is critical for the salinity horizontal advection in the upper layer. For instance, the location of this ridge determines the positive and negative boundary of SSS horizontal advection when the zonal currents behave in the same directions. This high-salinity ridge associated with the dipole mode is relatively stable near $170^{\circ} \mathrm{W}$ (Fig. 5d). As a result, the anomalous eastward current shows a dipole pattern, contributing to a negative SSS tendency west of $170^{\circ} \mathrm{W}$ and a positive SSS tendency east of it. Precipitation effect is relatively weak in a dipole mode (Fig. 5b). The ascending branch of the Walker circulation moves eastward and contributes to more precipitation $\left(1.6 \mathrm{~mm} /\right.$ day; $\left.180^{\circ}, 4^{\circ} \mathrm{N}\right)$ near the central equatorial Pacific.

Now we know the physical processes associated with the SSS monopole and dipole mode, but the relationship between these two modes and ENSO needs further investigation. We compare the equatorial variability of SST, SSS, rainfall, wind, and currents from an EP-El Niño composite
(Fig. 6, 1997/98 and 2015/16) and a CP-El Niño composite (Fig. 7; 1994/95, 2002/03, 2004/05, 2006/07, and 2009/10) to reveal related mechanisms responsible for SSS variability. The warm center is located in the eastern Pacific $\left(121^{\circ} \mathrm{W}\right)$ with SSTA exceeding $3{ }^{\circ} \mathrm{C}$ for the EP-El Niño composite (Fig. 6a). The CP-El Niño composite is weaker $\left(1.2^{\circ} \mathrm{C}\right)$ and focuses on the central equatorial Pacific (Fig. 7a). These suggest our classification of the two types of El Niño is reasonable for ECCO simulation. The evolution of SSSA during the CP- and EP-El Niño events corresponds to the monopole and dipole SSS mode, respectively (Figs. $6 \mathrm{~b}$ and $8 \mathrm{~b}$ ). During an EP-El Niño event, negative SSSAs appear near $160^{\circ} \mathrm{E}$ in January and peak at $174^{\circ} \mathrm{E}$ in August $(-0.40 \mathrm{psu})$. These negative signs extend eastward to as far as $130^{\circ} \mathrm{W}$ in November (Hasson et al. 2013), accompanied by more precipitation over the central to eastern equatorial Pacific (Fig. 6c). The westerly bursts at the western Pacific in January and covers the western to central-eastern Pacific in July, which induces an anomalous eastward current. The SSSAs during a CP-El Niño event are characterized by a dipole mode, with 
(a) MSI regressed Precipitation \& Wind

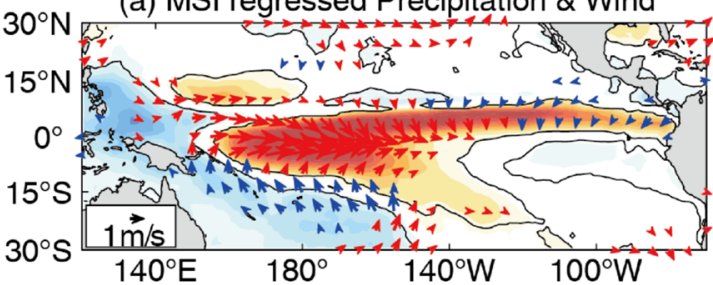

(b) DSI regressed Precipitation \& Wind

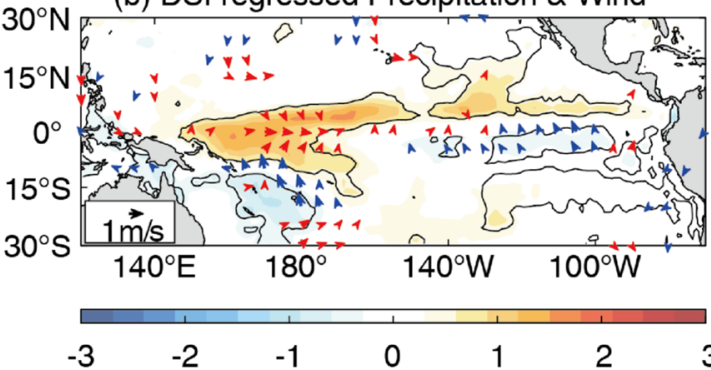

Fig. 5 MSI and DSI-regressed precipitation, sea surface wind, sea surface current, and sea surface salinity. The red/blue vectors denote eastward/westward anomalies of $(\mathbf{a}, \mathbf{b})$ winds and $(\mathbf{c}, \mathbf{d})$ currents. The shadings in (c, $\mathbf{d})$ denote the distribution of mean SSS plus MSI/DSIregressed SSSA. The $95 \%$ confidence levels of precipitation and cur- (c) MSI regressed Current \& SSS

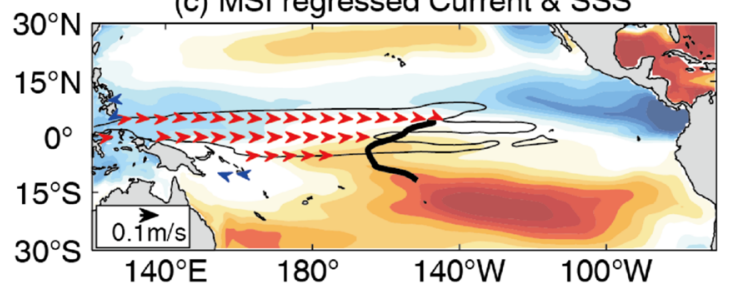

(d) DSI regressed Current \& SSS

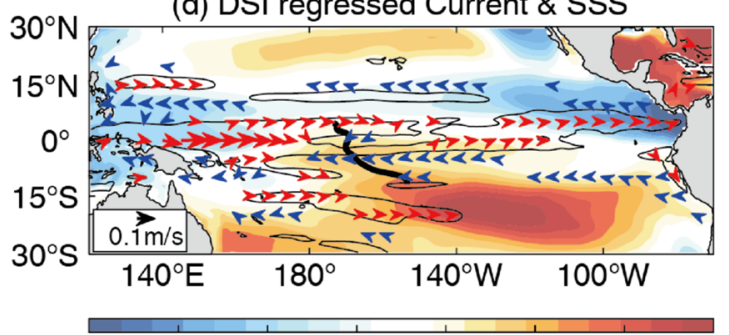

$\begin{array}{llllll}33.5 & 34 & 34.5 & 35 & 35.5 & 36\end{array}$

rent are shown with the black contours. The thick black lines in (c, d) are high-salinity ridges emanating from the southern subtropics. The data of precipitation and wind are from GPCP2.3 and NCEP2, respectively. The units in $(\mathbf{a} \& \mathbf{b})$ and $(\mathbf{c} \& \mathbf{d})$ are $1 \mathrm{~mm} / \mathrm{day}$ and 1 psu, respectively

(a) SST, EP-EI Niño

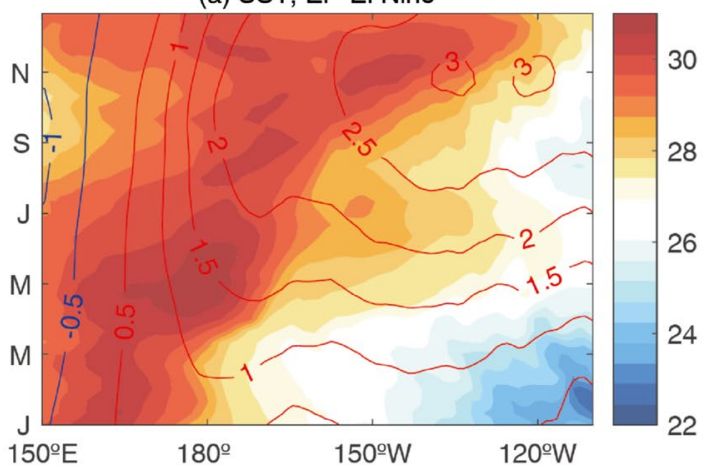

(c) Rainfall \& Wind, EP-El Niño

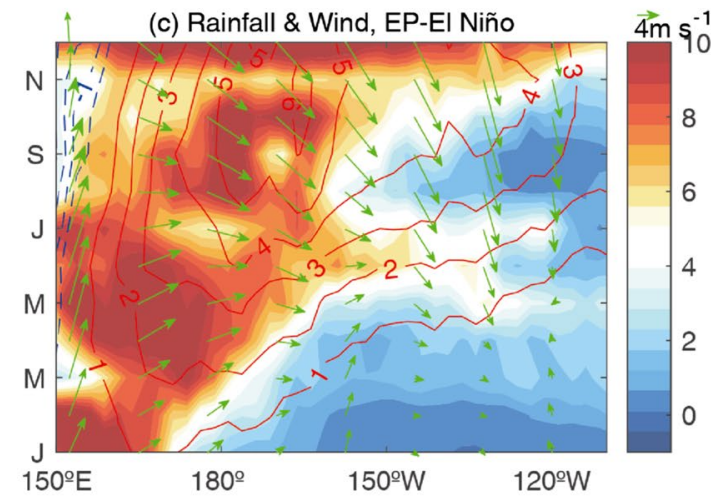

Fig. 6 Equatorial Pacific variability during an EP-El Niño composite (1997/98 and 2015/16). The shading and contours denote seasonal variability and corresponding anomalies. a SST and its anomaly; b SSS and its anomaly; c rainfall, its anomaly and sea surface wind (b) SSS, EP-EI Niño

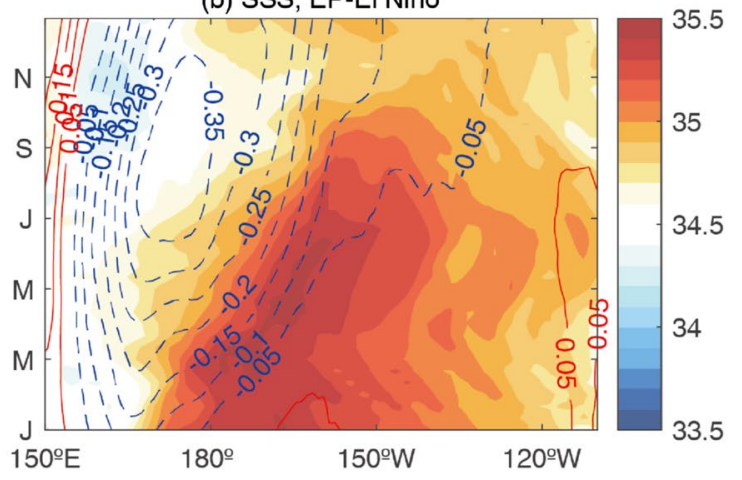

(d) Current, EP-EI Niño

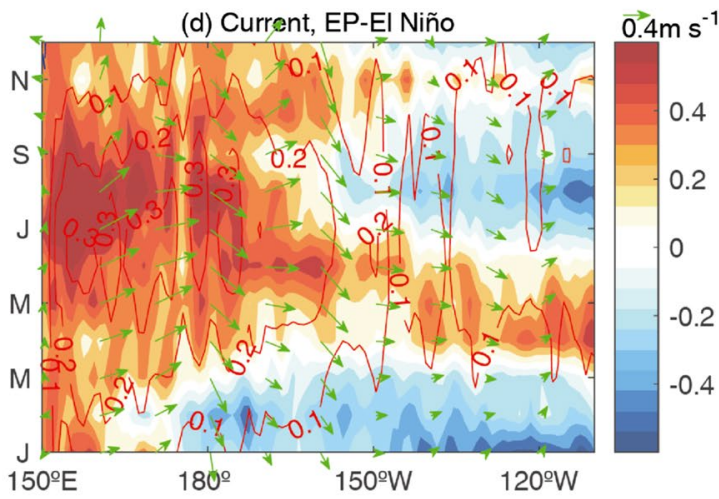

anomaly (vectors); d zonal velocity, its anomaly, and velocity anomaly (vectors). The SSS and SST are from ECCO product. The precipitation, wind, and surface current are from GPCP2.3, NCEP2, and OSCAR, respectively 

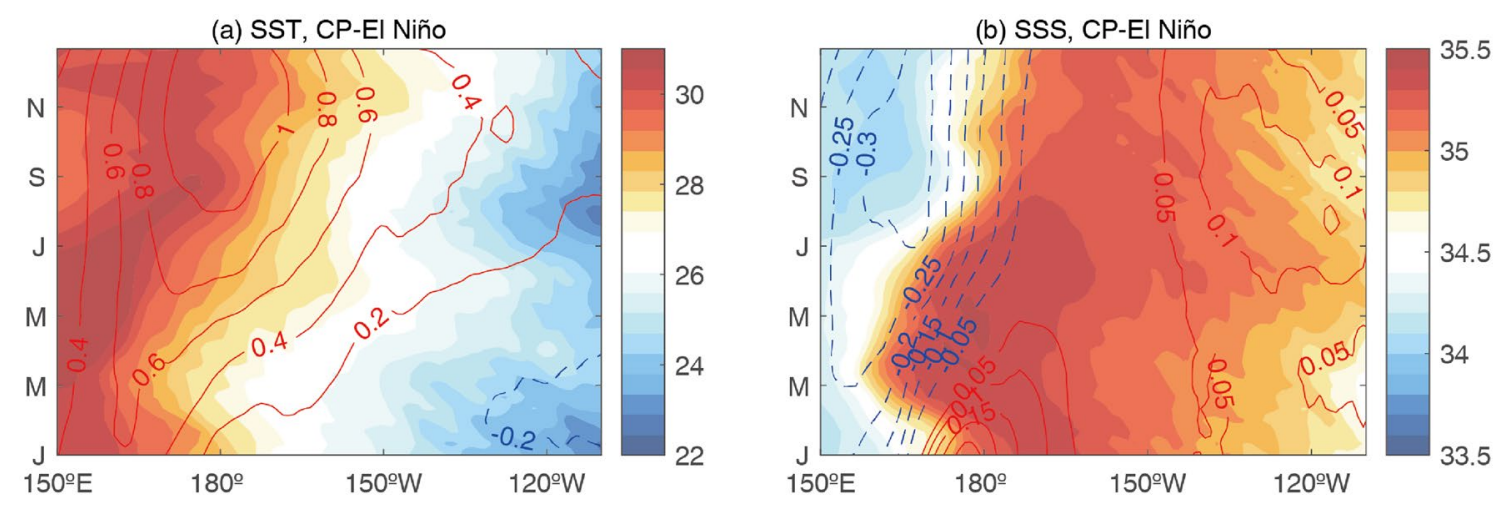

(c) Rainfall \& Wind, CP-EI Níño

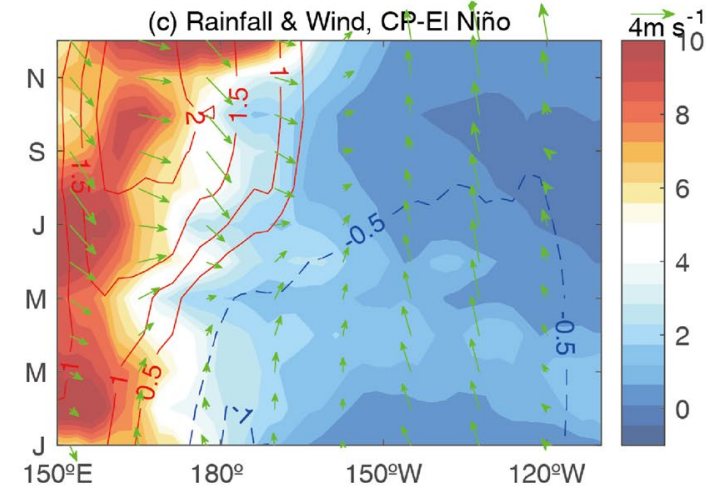

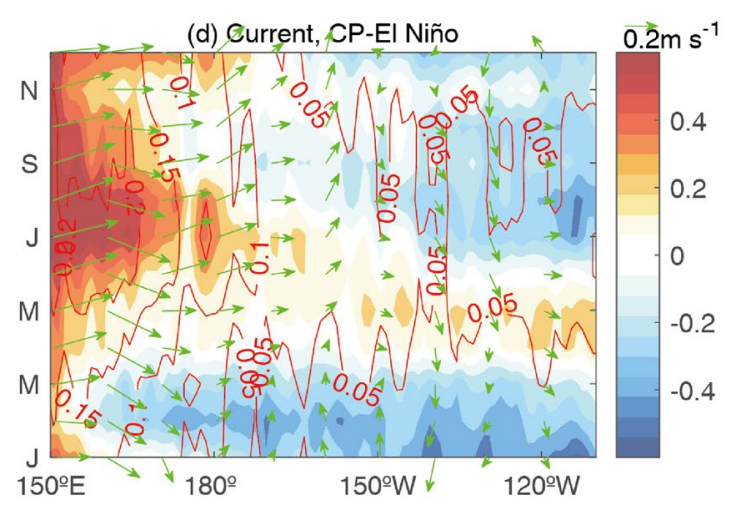

Fig. 7 Same as Fig. 6 expect for the CP-El Niño composite (1994/95, 2002/03, 2004/05, 2006/07, and 2009/10)

a negative center in the west $\left(-0.33 \mathrm{psu}, 168^{\circ} \mathrm{E}\right.$, October) and a positive center in the east $\left(0.16 \mathrm{psu}, 116^{\circ} \mathrm{W}\right.$, August). The development of this western center is highly related to the anomaly of precipitation, which is positive and limits in the west and central Pacific. Compared with the EP-El Niño composite, the zonal gradient of SSS is much larger and the high-salinity ridge is stabler near the central Pacific. Therefore, the eastern positive SSSA is obvious and attributes to the zonal SSS advection, although the anomalous eastward current is weaker than that during the EP-El Niño composite. In summary, the similar physical mechanisms indicate an EP-El Niño composite corresponds to the monopole mode. The dipole mode is critical for the development of a CP-El Niño event.

We further apply for mixed layer salinity (MLS) budget analysis to quantify the contributions of physical processes (Fig. 8). The physical processes responsible for the SSS variability consist of precipitation, evaporation, advection, entrainment, and mixing. The MLS budget suggests the evolution of an EP- and CP-El Niño event is mainly controlled by surface forcing and horizontal advection. For the EP-El Niño composite event, the MLS tendency is negative in the western-central Pacific at the beginning of the year and then develops and extends eastward to the eastern Pacific. The surface forcing is the primary process responsible for the
SSS variability in the western and eastern Pacific, and the horizontal advection dominates in the central Pacific (Fang and Zheng 2018). The MLS tendency during a CP-El Niño composite event shows a dipole pattern, with a robust freshening center in the western-central Pacific and weak salinization in the eastern Pacific. This dipole pattern attributes to the eastward horizontal advection, which transports fresh pool water in the western-central Pacific and the high-salinity water in the eastern Pacific. The subsurface processes can not be ignored and act to balance the surface forcing and advection in both composites. Recent simulation and observation have shown a clear SSS monopole pattern during the 2015/16 EP-El Niño and a SSS dipole pattern during the 2009/10 CP-El Niño event (Fig. 9).

\section{Variability under global warming}

Paleoclimate records and climate models indicate that the interannual variability in the tropical Pacific will still be one of the most prominent phenomena in the world's climate system under global warming (Vecchi and Wittenberg 2010). How ENSO responses to increasing greenhouse gases lack consensus among model simulations, observations, and proxies (Vecchi et al. 2006; Zhang and Song 2006). Previous 

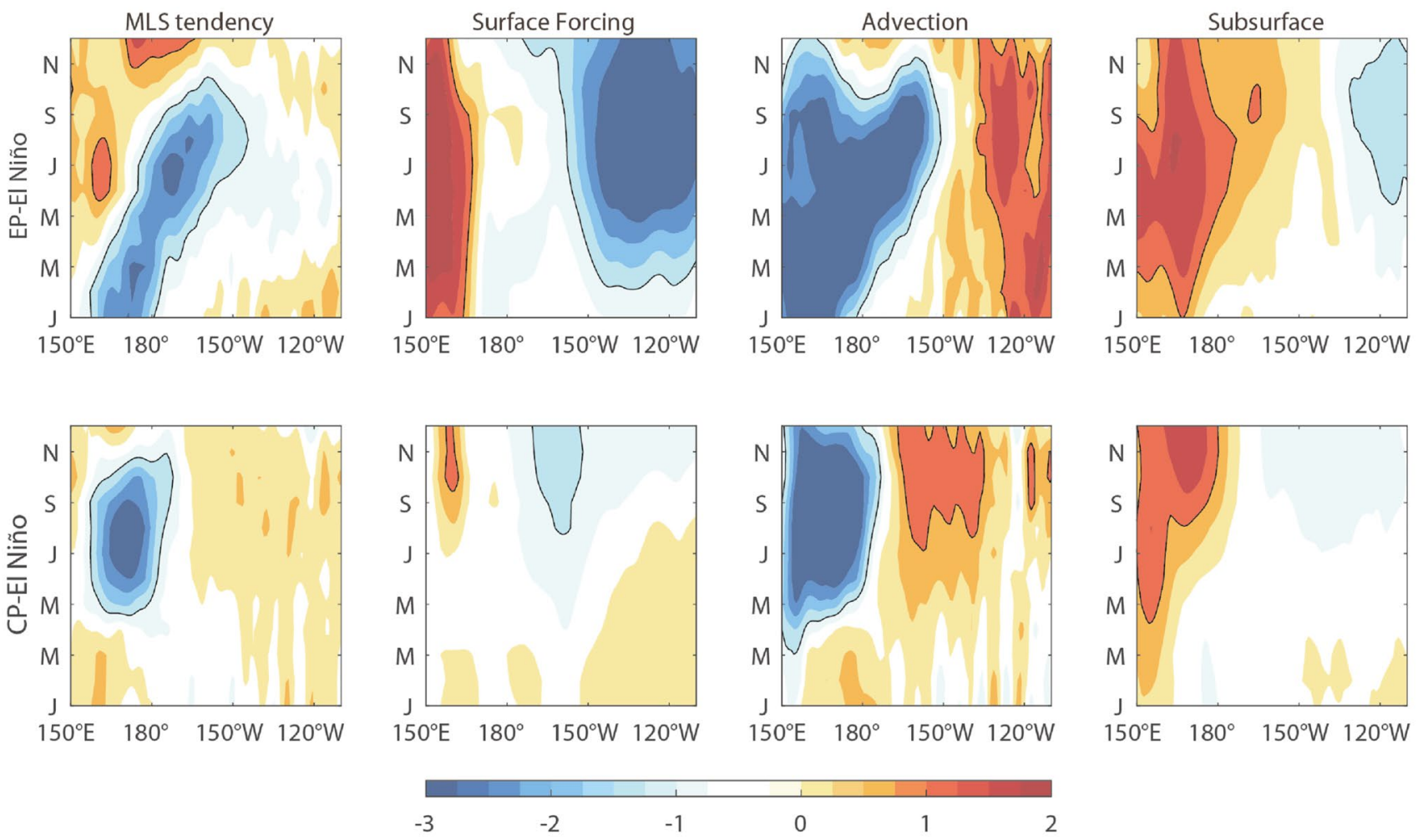

Fig. 8 Equatorial mixed layer salinity budget terms during an EP-El Niño (top row) and CP-El Niño (bottom row) composite. The budget terms include MLS tendency, surface forcing, horizontal advection,

and surface processes. The results are from ECCO product. The seasonal cycles are removed. The units are $10^{-8} \mathrm{psu} / \mathrm{s}$
Fig. 9 December-February mean SSSA during 2009/10 and 2015/16. The shading and contours denote the result from ECCO product and observtion (Argo), respectively. The units are 1 psu (a) SSS Anomaly, 2009/10 El Niño (NDJ)

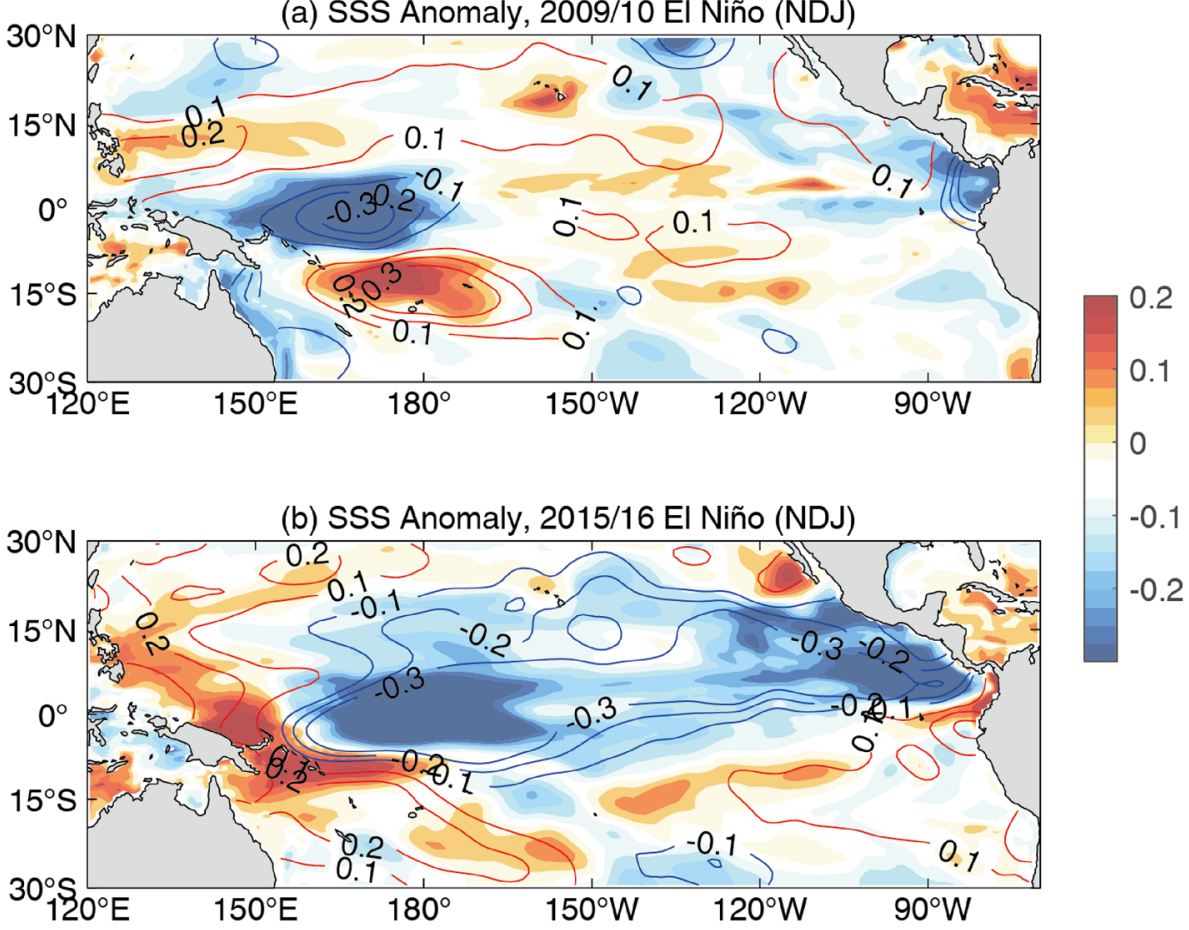


studies using conventional ENSO indices did not reach an agreement on future variability, either (Watanabe et al. 2012; Cai et al. 2015). Cai et al. (2018) found a robust increase in future EP-ENSO SST variability among CMIP5 interannual modes based on the E index (Takahashi et al. 2011). Recently, CMIP developed into its sixth phase, which provides multi-model climate projections based on alternative scenarios of future emissions. The new SSS indices emphasizing the water circulation may provide a new perspective on the future ENSO variability.
Ten model outputs of historical simulations and SSP2-4.5 ScenarioMIP experiments (Table 3) are applied to identify the interannual variability of SSS under global warming. We compare the interannual variance of SSS in the tropical Pacific from these models with observation (EN4) for the period of 1929-2014 (Fig. 10). SSS varies significantly in the western and central equatorial Pacific from the 4 model outputs (EC-Earth3, EC-Earth3-Veg, GFDL-CM4, and MIROC6), whose variance is about the same with observation. The other 6 model results show the interannual
Table 3 Details of 10 models from CMIP6 and EN4

observation

\begin{tabular}{|c|c|c|c|c|c|c|c|c|c|}
\hline \multicolumn{2}{|c|}{ Models/Obs } & \multicolumn{2}{|l|}{ MSI } & \multicolumn{2}{|l|}{ DSI } & \multicolumn{2}{|c|}{ CP-El Niño } & \multicolumn{2}{|c|}{ EP-El Niño } \\
\hline & & Hist & SSP245 & Hist & SSP245 & Hist & SSP245 & Hist & SSP245 \\
\hline Obs & EN4 & 0.17 & & 0.20 & & 10 & & 6 & \\
\hline 1 & EC-Earth3 & 0.17 & 0.31 & 0.33 & 0.52 & 10 & 19 & 6 & 19 \\
\hline 2 & EC-Earth3-Veg & 0.15 & 0.31 & 0.35 & 0.50 & 12 & 17 & 11 & 15 \\
\hline 3 & GFDL-CM4 & 0.11 & 0.22 & 0.39 & 0.49 & 11 & 16 & 13 & 14 \\
\hline 4 & MIROC6 & 0.37 & 0.45 & 0.45 & 0.55 & 15 & 18 & 11 & 14 \\
\hline 5 & BCC-CSM2-MR & 0.06 & 0.10 & 0.18 & 0.20 & 13 & 15 & 12 & 13 \\
\hline 6 & CanESM5 & 0.16 & 0.20 & 0.25 & 0.35 & 12 & 19 & 6 & 15 \\
\hline 7 & CNRM-CM6-1 & 0.14 & 0.16 & 0.29 & 0.36 & 11 & 14 & 13 & 10 \\
\hline 8 & CNRM-ESM2-1 & 0.11 & 0.15 & 0.24 & 0.27 & 14 & 16 & 3 & 16 \\
\hline 9 & IPSL-CM6A-LR & 0.04 & 0.07 & 0.21 & 0.35 & 7 & 16 & 5 & 18 \\
\hline 10 & UKESM1-0-LL & 0.16 & 0.24 & 0.34 & 0.45 & 11 & 17 & 10 & 18 \\
\hline 11 & Ensemble & 0.15 & 0.22 & 0.30 & 0.40 & 11.6 & 16.7 & 9 & 15.2 \\
\hline
\end{tabular}

The third to sixth columns show the standard deviations of MSI and DSI. The latter four columns denote the numbers of the CP and EP-El Niño events for the period of 1929-2014 and 2015-2100. The Hist and SSP245 denote historical experiments (1929-2014) and Shared Socioeconomic Pathway 2-4.5 ScenarioMIP experiments (2015-2100)

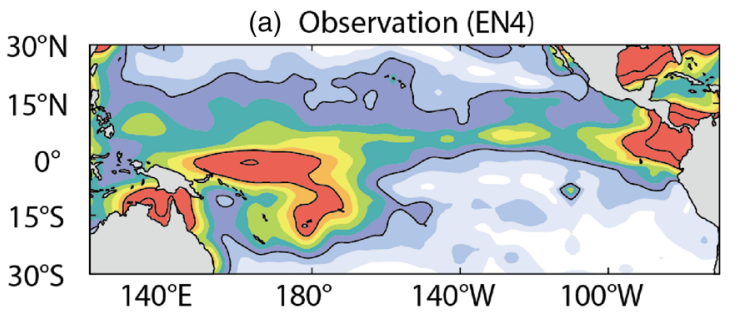

(c) CMIP6 mode 7 (CNRM-CM6-1)

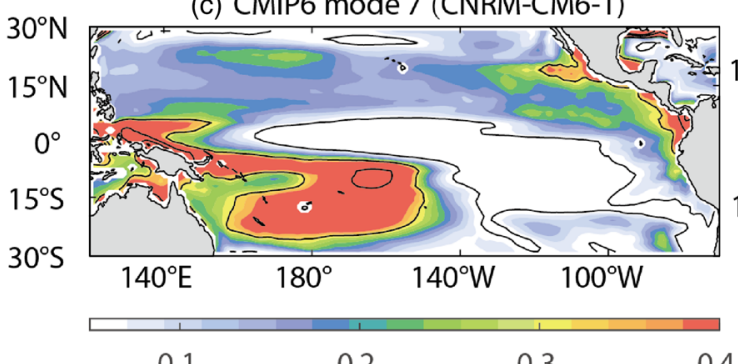

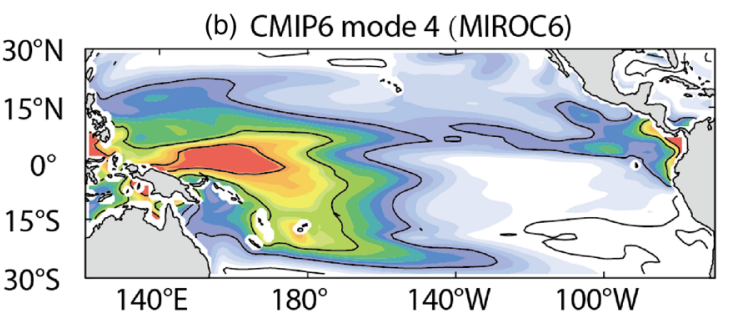

(d)

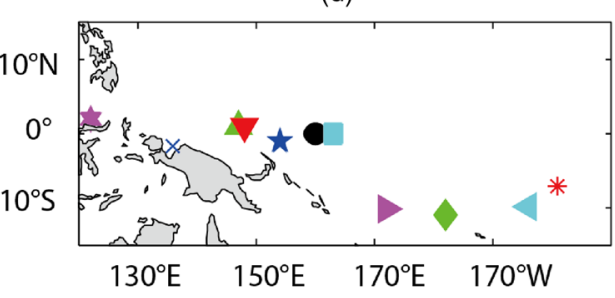

PEN4 $\mathrm{m}-01$ $\mathrm{m}-02$
$\times \mathrm{m}-03$ * $\mathrm{m}-03$ * $\mathrm{m}-05$ m-06 $\mathrm{m}-07$
$\mathrm{~m}-08$ $m-08$
$+m-09$ $\times$ m-10
0.1
0.2
0.3
0.4

Fig. 10 Interannual variability of SSS in the tropical Pacific from EN4 and model simulations. Interannual standard deviations of SSS from a EN4, b MIROC6, c CNRM-CM6-1 for the period from 1929 to 2014. d The locations for interannual variability maximum of SSS 
variability of SSS mainly is located in the SPCZ. We perform an EOF analysis to de-trend monthly SSSAs over the period 1929-2014. These 4 models simulate a monopole SSS mode and a dipole SSS mode clearly (Fig. 11). Consistent with the ECCO results, the MSI-regressed precipitation and DSI-regressed current from the 4 models indicate that precipitation and zonal advection are closely related to the monopole and dipole SSS mode, respectively (not shown). Therefore, these 4 models are selected to study the difference between the two periods.

We compare the standard deviations of the MSI and DSI indices in the present-day control period (1929-2014) and future climate change (2015-2100) period, both of which span 86 years. All models simulate a greater variance in the MSI and DSI indices in the future period (Fig. 12a and Table 3). Compared with the historical experiments, the future standard deviations of the ensemble-mean MSI and DSI increase from 0.15 to $0.22 \mathrm{psu}$ (increase $47 \%$ ) and 0.30 to $0.40 \mathrm{psu}$ (increase $33 \%$ ), respectively. As we defined, the CP- and EP-El Niño events are distinguished with [MSI $>0$, $\mathrm{DSI}>0$, MSI + DSI $>1$ s.d.] and [MSI $>0$, DSI $<0$, MSIDSI $>1$ s.d.] (Fig. 3 and Table 1). These increases in variance translate to a $44 \%$ increase in the occurrence of CP-El Niño events and a $69 \%$ increase in the occurrence of EP-El Niño events. In other words, these results suggest that the occurrences of CP- and EP-El Niño events would increase 5.9 and 7.2 per hundred years as the climate warms up, respectively. The CP-El Niño events increase in all models, with the increasing trends ranges from 2.3 to 10.5 per hundred years. However, there is no inter-model consensus for
EP-El Niño events, with 9 of the 10 models producing an increase in their occurrences.

We find that the change in mean climate is robust and this explains the increased variability of both the CP- and EP-El Niño events. The increased EP-El Niño variability is attributed to the upper layer SST variability, an EP-El Niñolike warming pattern (Cai et al. 2018). SST increases fastest in the eastern equatorial Pacific (Fig. 12c), which facilitates more frequent atmospheric convection in the region. The decreased temperature gradient across the equatorial Pacific is coupled with anomalous westerly (Fig. 12e). The modulation of coupling between the ocean and the atmosphere results in more precipitation in the tropical Pacific. As the precipitation is the key process to the SSS monopole mode, this SST means the state favors the development of this mode. The increasing variability of monopole mode further enhances the EP-El Niño.

The contributors of the CP-El Niño variability are not only limited in the upper layer but deepened to the subsurface. The increased vertical stratification plays a critical role in the change of the CP-El Niño variability. The water warms and freshens faster in the upper layer than at the subsurface, suggesting the future stratification is more stable than present-day in the equatorial Pacific (Fig. 12c, d). For the future period, the thermocline deepens $\left(15 \mathrm{~m}, 92^{\circ} \mathrm{W}\right)$ in the eastern but shoals $\left(4 \mathrm{~m}, 164^{\circ} \mathrm{W}\right)$ in the central and western equatorial Pacific, which leads to a flatter thermocline across the equatorial Pacific. The more stable stratification and flatter thermocline hinder water exchange between the upper layer and subsurface but favor the horizontal advection. (a) SSS EOF1 (39\%), Observation

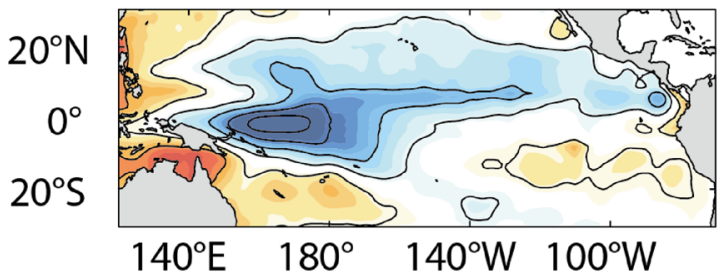

(c) Monopole SSS Mode, CMIP6

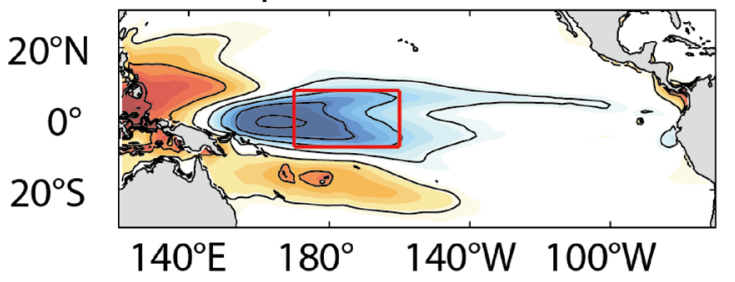

(b) SSS EOF2 (24\%), Observation

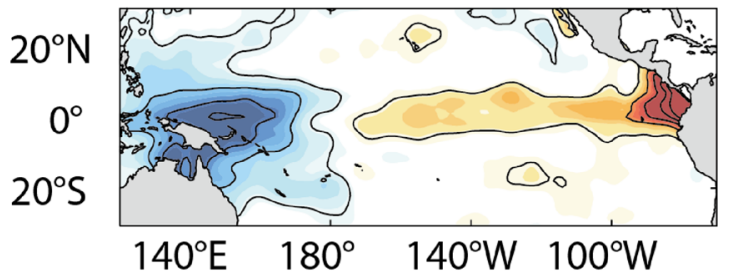

(d) Dipole SSS Mode, CMIP6

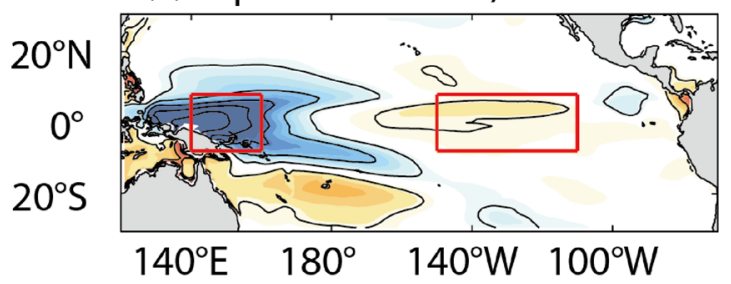

$$
\begin{array}{lllllll}
-0.3 & -0.2 & -0.1 & 0 & 0.1 & 0.2 & 0.3
\end{array}
$$

Fig. 11 Monopole and Dipole SSS mode from observation (EN4) and CMIP6 historical experiments composite for the period 1929 to 2014 . The units are $1 \mathrm{psu}$ 


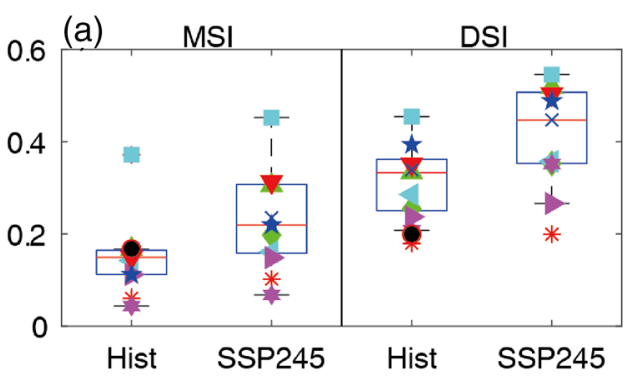

(c)

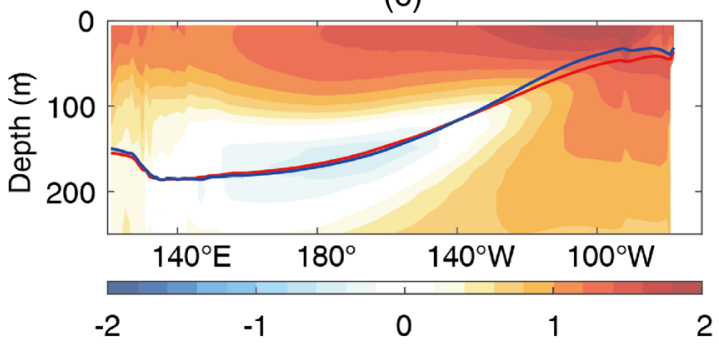

(e)

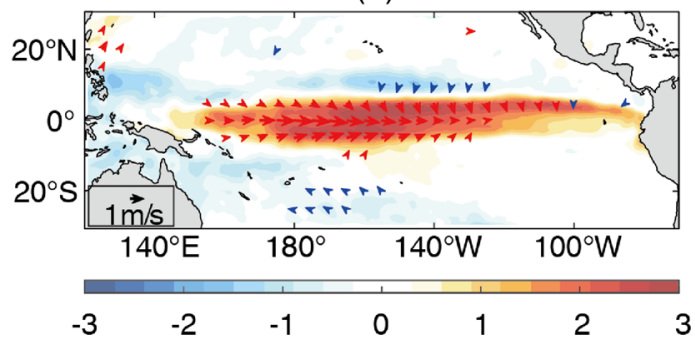

Fig. 12 Monopole and dipole SSS mode variability under global warming from the CMIP6 models. a Standard deviations of MSI and DSI indices for the historical (Hist, 1929-2014) and future (SSP245, 2015-2100) experiments from observation (EN4) and 10 models. b Number of CP- and EP-El Niño events that occurred in two 86-year periods. The changes of selected-model-mean in equatorial $\mathbf{c}$ temperature and salinity $\mathbf{d}$ between historical and future climates. The blue and red lines represent thermocline (temperature $=20^{\circ} \mathrm{C}$ ) for the historical and future experiments, respectively. e The difference of MSI-

The western Pacific freshens significantly and high-salinity ridges emanating from the southern subtropics is still located at the central-eastern tropical Pacific in the future (Fig. 12f), which implies that the anomalous eastward currents would lead to a robust dipole mode. Therefore, the variability of dipole mode would also intensify and contribute to the increased CP-El Niño variability.

\section{Summary and discussions}

In the past decades, the phase of ENSO is changing with more CP-El Niño events. Different and significant climate influences (Weng et al. 2007; Hong et al. 2011) between two types El Niño asked for a method to distinguish them. Trenberth and Stepaniak (2001) suggested that it is needed

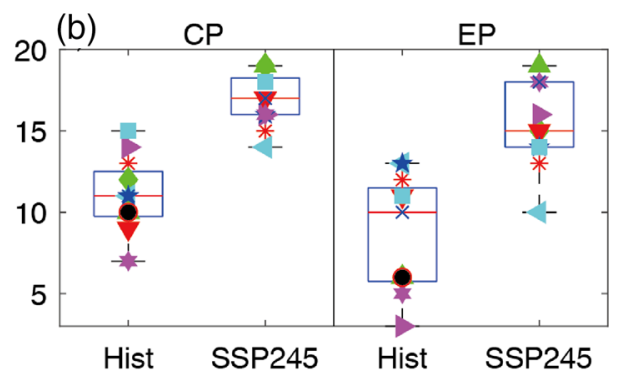

(d)

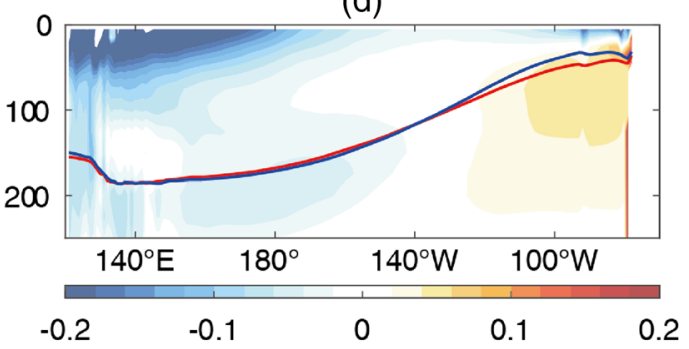

(f)

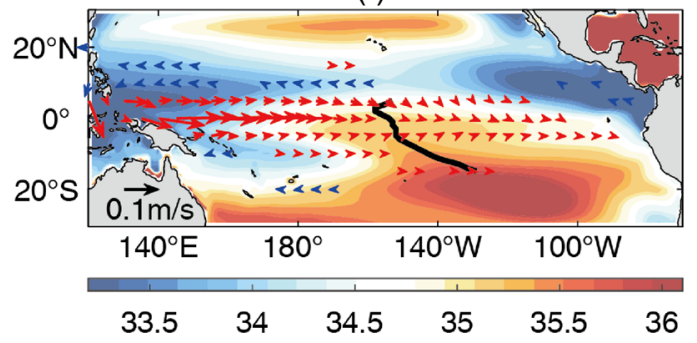

regressed precipitation (shading) and $10 \mathrm{-m}$ wind (vector) between historical and future experiments from models 1-4. f The difference of DSI-regressed sea surface current (vector) and SSS between historical and future experiments from models $1-4$. The thick black line in $\mathbf{f}$ is a high-salinity ridge emanating from the southern subtropics. The red/blue vectors indicate eastward/westward anomalies. The units for shading in (c, d, e, and f) are $1^{\circ} \mathrm{C}, 1 \mathrm{psu}, 1 \mathrm{~mm} / \mathrm{day}$, and $1.0 \mathrm{psu}$, respectively

at least two indices to distinguish the two types of events. Indices are proposed from different perspectives that emphasize different aspects of the ENSO evolution. Most commonly, classification methods are based on SST, including Niño3 and Niño4 (Yeh et al. 2009), Niño3 and EMI (Hendon et al. 2009), Niño3.4 and EOF PCs (Kao and Yu 2009), E and $C$ indices (Takahashi et al. 2011), which emphasized the air-sea coupling interaction. Using different variables to describe ENSO is helpful to understand its behavior, impacts, and mechanisms. For examples, Singh et al. (2011) investigated the SSS variability on the western-central equatorial Pacific and SPCZ, and introduced two indices, SSSENSO and SSS-El Niño, to identify the ENSO phases and the event types; while Qu and Yu (2014) found the differences of SSS variability in the southeastern Pacific (SEPSI) between CP- and EP-El Niño. 
In this study, observed data and model simulation were used to characterize the interannual variability of SSS and related physical processes in the tropical Pacific. The first two SSSA EOF PCs can be well estimated by a combination of the SSS variability in region $A\left[8^{\circ} \mathrm{S}-8^{\circ} \mathrm{N}\right.$, $\left.140^{\circ}-160^{\circ} \mathrm{E}\right], \mathrm{B}\left[8^{\circ} \mathrm{S}-8^{\circ} \mathrm{N}, 170^{\circ} \mathrm{E}-160^{\circ} \mathrm{W}\right], \mathrm{C}\left[8^{\circ} \mathrm{S}-8^{\circ} \mathrm{N}\right.$, $\left.150^{\circ}-110^{\circ} \mathrm{W}\right]$. We found that the ENSO phase and type are well classified by the $45^{\circ}$ rotation axes of the first two PCs, defined as MSI and DSI, respectively. We proposed that the interannual variability of SSS consists of the two corresponding modes, a monopole and a dipole SSS mode, which explain the similarities and differences between the CP- and EP-El Niño, respectively. The monopole mode is characterized by a significant negative SSSA center over the western and central-eastern equatorial Pacific, while centers with opposite signs is located in the western and eastern equatorial Pacific is the primary feature of the dipole mode.

Different physical processes are at work in modulating the SSS variability of the monopole and dipole modes (Fig. 13). The main characters of the two modes can be well captured by the SSSA in the western, central, and eastern equatorial Pacific. Atmospheric forcing, particularly precipitation, is primarily responsible for the monopole mode, while ocean dynamics (horizontal advection) is more important for the dipole mode. The modulation of the Walker circulation results in more precipitation in the central-eastern equatorial Pacific, which enhances the negative SSS tendency of the monopole mode. For the dipole mode, fresh water is trapped to the west of $170^{\circ} \mathrm{W}$, where a stable high-salinity ridge emanates from the southern subtropics. As a consequence, anomalous eastward current transports fresh water to the western Pacific and salty water to the eastern Pacific and eventually forms a dipole pattern. Therefore, the MSI and DSI indices emphasize the zonal water transport over the tropical Pacific through the atmospheric and oceanic processes.

The proposed indices also provide a new perspective to study the variability of ENSO under global warming. Model experiments also show a clear monopole and dipole mode in historical and future climates. The future scenario increases by $47 \%$ and $33 \%$ of the variability of the monopole and dipole SSS mode, which increases both the CP- and EP-El Niño variance. The change in mean climate contributes to the variability of CP- and EP-El Niño. The increase in CP-El Niño variability is largely due to global-warming-induced enhanced vertical stratification in the upper layer, which favors zonal advection variability and forms a dipole SSS mode. An EP-El Niño-like warming pattern contributes to the increase in EP-El Niño. The precipitation in the centraleastern tropical Pacific would enhance this pattern and contribute to the development of the monopole SSS mode.

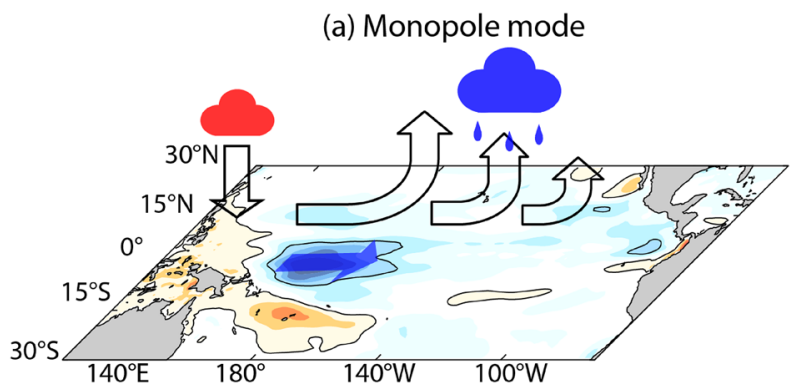

(b) Dipole mode

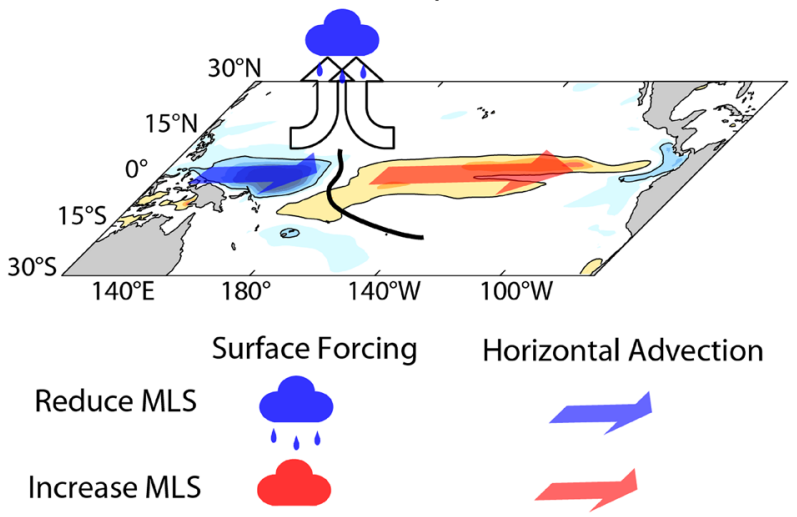

Fig. 13 The schematic of the SSS variability during (a) monopole and (b) dipole modes. The contours and shading indicate salinity anomalies from ECCO product. The symbols with blue (red) denote processes that contribute to salinity decrease (increase). The cloud and vector represent anomalous surface forcing and anomalous horizontal advection, respectively. The hollow arrow indicates the anomalous atmospheric circulation. The thick black line denotes the highsalinity ridge emanating from the southern subtropics

Author contributions This study was started when JC visited UCLA and was completed at SCSIO. TQ, YD and JC conceived the idea, designed the analysis. JC wrote the paper. JC analyzed the data and carried out figure illustration. All authors provided guidance to improving the analysis and reviewed the manuscript. The authors thank YQ (National Marine Environmental Forecasting Center), and ZL (Key Laboratory of Marine Science and Numerical Modeling) for valuable discussions.

Funding This work is supported by the National Natural Science Foundation of China $(42,006,028,41,830,538,42,090,042)$, the Chinese Academy of Sciences (XDB42010305, XDA15020901, 133244KYSB20190031), the National Basic Research Program of China (2018YFA0605704), and the Southern Marine Science and Engineering Guangdong Laboratory (Guangzhou) (GML2019ZD0303, 2019BT02H594). J. Chi is also supported by the Open Fund of the Key Laboratory of Ocean Circulation and Waves (KLOCW2004), State Key Laboratory of Tropical Oceanography (South China Sea Institute of Oceanology Chinese Academy of Sciences) (LTOZZ2101) and the China Scholarship Council.

Data availability The datasets generated during and/or analysed during the current study are available from the corresponding author on reasonable request. 
Code availability The codes during and/or analysed during the current study are available from the corresponding author on reasonable request.

\section{Declarations}

Conflicts of interest The authors have no relevant financial or nonfinancial interests to disclose.

Open Access This article is licensed under a Creative Commons Attribution 4.0 International License, which permits use, sharing, adaptation, distribution and reproduction in any medium or format, as long as you give appropriate credit to the original author(s) and the source, provide a link to the Creative Commons licence, and indicate if changes were made. The images or other third party material in this article are included in the article's Creative Commons licence, unless indicated otherwise in a credit line to the material. If material is not included in the article's Creative Commons licence and your intended use is not permitted by statutory regulation or exceeds the permitted use, you will need to obtain permission directly from the copyright holder. To view a copy of this licence, visit http://creativecommons.org/licenses/by/4.0/.

\section{References}

Ashok K, Behera SK, Rao SA, Weng H, Yamagata T (2007) El Niño Modoki and its possible teleconnection. J Geophys Res-Oceans 112:1-27. https://doi.org/10.1029/2006JC003798

Bosc C, Delcroix T, Maes C (2009) Barrier layer variability in the western Pacific warm pool from 2000 to 2007. J Geophys ResOceans 114:1-14. https://doi.org/10.1029/2008JC005187

Cai W et al (2014) Increasing frequency of extreme El Nino events due to greenhouse warming. Nat Clim Chang 4:111-116. https://doi. org/10.1038/Nclimate2100

Cai W et al (2015) ENSO and greenhouse warming. Nat Clim Chang 5:849-859. https://doi.org/10.1038/Nclimate2743

Cai W et al (2018) Increased variability of eastern Pacific El Nino under greenhouse warming. Nature 564:201-206. https://doi.org/ 10.1038/s41586-018-0776-9

Cha S-C, Moon J-H, Song YT (2018) A recent shift toward an El Niñolike ocean state in the tropical pacific and the resumption of ocean warming. Geophys Res Lett 45(21):11,885-811,894. https://doi. org/10.1029/2018g1080651

Chi J, Du Y, Zhang Y, Nie X, Shi P, Qu T (2019) A new perspective of the 2014/15 failed El Nino as seen from ocean salinity. Sci Rep 9:1-9. https://doi.org/10.1038/s41598-019-38743-z

Chiodi AM, Harrison DE (2013) El Niño impacts on seasonal U.S. atmospheric circulation, temperature, and precipitation anomalies: The OLR-event perspective*. J Clim 26:822-837. https://doi.org/ 10.1175/jcli-d-12-00097.1

Delcroix T (1998) Observed surface oceanic and atmospheric variability in the tropical Pacific at seasonal and ENSO timescales: a tentative overview. J Geophys Res-Oceans 103:18611-18633. https://doi.org/10.1029/98JC00814

Delcroix T, Picaut J (1998b) Zonal displacement of the western equatorial Pacific “fresh pool.” J Geophys Res-Oceans 103:1087-1098. https://doi.org/10.1029/97JC01912

Delcroix T, McPhaden M (2002) Interannual sea surface salinity and temperature changes in the western Pacific warm pool during 1992-2000. J Geophys Res-Oceans 107:SRF 3-1-SRF 3-17. https://doi.org/10.1029/2001JC000862
Delcroix T, Picaut J (1998) Zonal displacement of the western equatorial Pacific "fresh pool", J Geophys Res 103:1087-1098

Du Y, Zhang YH, Shi JC (2019) Relationship between sea surface salinity and ocean circulation and climate change. Sci China Earth Sci 62:771-782. https://doi.org/10.1007/s11430-018-9276-6

Fang X, Zheng F (2018) Simulating Eastern- and Central-Pacific Type ENSO Using a Simple Coupled Model. Adv Atmos Sci 35:671681. https://doi.org/10.1007/s00376-017-7209-9

Fukumori I (2002) A partitioned Kalman filter and smoother. Mon Weather Rev 130:1370-1383. https://doi.org/10.1175/15200493(2002)130\%3c1370:APKFAS\%3e2.0.CO;2

Gao S, Qu T, Nie X (2014) Mixed layer salinity budget in the tropical Pacific Ocean estimated by a global GCM. J Geophys ResOceans 119:8255-8270. https://doi.org/10.1002/2014JC010336

Gent PR, McWilliams JC (1990) Isopycnal mixing in ocean circulation models. J Phys Oceanogr 20:150-155. https://doi.org/ 10.1175/1520-0485(1990)020\%3c0150:IMIOCM\%3e2.0.CO;2

Good SA, Martin MJ, Rayner NA (2013) EN4: Quality controlled ocean temperature and salinity profiles and monthly objective analyses with uncertainty estimates. J Geophys Res-Oceans 118:6704-6716. https://doi.org/10.1002/2013jc009067

Graham NE (1994) Decadal scale variability in the tropical and North Pacific during the 1970s and 1980s: observations and model results Climate dynamics 10:135-162

Hasson AEA, Delcroix T, Dussin R (2013) An assessment of the mixed layer salinity budget in the tropical Pacific Ocean. Observations and modelling (1990-2009). Ocean Dyn 63:179-194. https://doi.org/10.1007/s10236-013-0596-2

Hendon HH, Lim E, Wang G, Alves O, Hudson D (2009) Prospects for predicting two flavors of El Niño. Geophys Res Lett 36. https://doi.org/10.1029/2009g1040100

Hong C-C, Li Y-H, Li T, Lee M-Y (2011) Impacts of central Pacific and eastern Pacific El Niños on tropical cyclone tracks over the western North Pacific. Geophys Res Lett 38:1-9. https://doi.org/ 10.1029/2011g1048821

Jin F-F (1997) An equatorial ocean recharge paradigm for ENSO. Part I: Conceptual model. J Atmos Sci 54:811-829. https://doi. org/10.1175/1520-0469(1997)054\%3c0811:AEORPF\%3e2.0. $\mathrm{CO} ; 2$

Kalnay E et al (1996) The NCEP/NCAR 40-Year reanalysis project. Bull Amer Meteorol Soc 77:437-471. https://doi.org/10.1175/ 1520-0477(1996)077\%3c0437:TNYRP\%3e2.0.CO;2

Kao HY, Yu JY (2009) Contrasting Eastern-Pacific and Central-Pacific Types of ENSO. J Clim 22:615-632. https://doi.org/10.1175/ 2008JCLI2309.1

Kim S-B, Fukumori I, Lee T (2006) The closure of the ocean mixed layer temperature budget using level-coordinate model fields. J Atmos Ocean Technol 23:840-853. https://doi.org/10.1175/ JTECH1883.1

Kug J-S, Jin F-F, An S-I (2009) Two types of El Niño events: cold tongue El Niño and warm pool El Niño. J Clim 22:1499-1515. https://doi.org/10.1175/2008JCLI2624.1

Large WG, McWilliams JC, Doney SC (1994) Oceanic vertical mixing: a review and a model with a nonlocal boundary layer parameterization. Rev Geophys 32:363-403. https://doi.org/10.1029/ 94RG01872

Larkin NK, Harrison D (2005) Global seasonal temperature and precipitation anomalies during El Niño autumn and winter. Geophys Res Lett 32:L16705. https://doi.org/10.1029/2005GL022860

Lee T, Fukumori I (2003) Interannual-to-decadal variations of tropical-subtropical exchange in the pacific ocean: boundary versus interior pycnocline transports. J Clim 16:4022-4042. https://doi. org/10.1175/1520-0442(2003)016\%3c4022:IVOTEI\%3e2.0.CO;2

Maes C, McPhaden MJ, Behringer D (2002) Signatures of salinity variability in tropical Pacific Ocean dynamic height anomalies. 
J Geophys Res-Oceans 107:1-13. https://doi.org/10.1029/2000J $\mathrm{C} 000737$

Maes C (2008) On the ocean salinity stratification observed at the eastern edge of the equatorial Pacific warm pool. J Geophys ResOceans 113. https://doi.org/10.1029/2007jc004297

Marshall J, Adcroft A, Hill C, Perelman L, Heisey C (1997) A finitevolume, incompressible Navier Stokes model for studies of the ocean on parallel computers. J Geophys Res-Oceans 102:57535766. https://doi.org/10.1029/96JC02775

McPhaden MJ, Zebiak SE, Glantz MH (2006) ENSO as an integrating concept in Earth science. Science 314:1740-1745. https://doi.org/ $10.1126 /$ science. 1132588

McPhaden MJ, Busalacchi AJ, Anderson DLT (2010) A toga retrospective. Oceanography 23:86-103. https://doi.org/10.5670/oceanog. 2010.26

Miller AJ, Cayan DR, Barnett TP, Graham NE, Oberhuber JM (1994) The 1976-77 climate shift of the Pacific Ocean Oceanography $7: 21-26$

Moon JH, Song YT, Lee H (2015) PDO and ENSO modulations intensified decadal sea level variability in the tropical Pacific. J Geophys Res 120(12):8229-8237. https://doi.org/10.1002/2015j c011139

Murtugudde R, Busalacchi AJ (1998) Salinity effects in a tropical ocean model. J Geophys Res 103:3283-3300. https://doi.org/10. $1029 / 97$ jc02438

North GR, Bell TL, Cahalan RF, Moeng FJ (1982) Sampling errors in the estimation of empirical orthogonal functions. Mon Weather Rev 110:699-706. https://doi.org/10.1175/1520-0493(1982)110\% 3c0699:Seiteo\%3e2.0.Co;2

Picaut J, Masia F, duPenhoat Y (1997) An advective-reflective conceptual model for the oscillatory nature of the ENSO. Science 277:663-666. https://doi.org/10.1126/science.277.5326.663

Picaut J, Ioualalen M, Delcroix T, Masia F, Murtugudde R, Vialard J (2001) The oceanic zone of convergence on the eastern edge of the Pacific warm pool: a synthesis of results and implications for El Niño-Southern Oscillation and biogeochemical phenomena. J Geophys Res-Oceans 106:2363-2386. https://doi.org/10.1029/ 2000JC900141

Qi J et al (2019) Salinity variability in the tropical Pacific during the Central-Pacific and Eastern-Pacific El Niño events. J Mar Syst 199:1-14. https://doi.org/10.1016/j.jmarsys.2019.103225

Qu T, Yu J-Y (2014) ENSO indices from sea surface salinity observed by Aquarius and Argo. J Oceanogr 70:367-375. https://doi.org/ 10.1007/s10872-014-0238-4

Qu T, Gao S, Fukumori I (2011) What governs the North Atlantic salinity maximum in a global GCM? Geophys Res Lett 38:1-6. https://doi.org/10.1029/2011GL046757

Qu T, Song TY, Maes C (2014) Sea surface salinity and barrier layer variability in the equatorial Pacific as seen from Aquarius and Argo. J Geophys Res-Oceans 119:15-29. https://doi.org/10.1002/ 2013JC009375

Rasmusson EM, Carpenter TH (1982) Variations In tropical sea-surface temperature and surface wind fields associated with the Southern oscillation El-Nino. Mon Weather Rev 110:354-384. https://doi. org/10.1175/1520-0493(1982)110\%3c0354:Vitsst\%3e2.0.Co;2

Redi MH (1982) Oceanic isopycnal mixing by coordinate rotation. J Phys Oceanogr 12:1154-1158. https://doi.org/10.1175/15200485(1982)012\%3c1154:OIMBCR\%3e2.0.CO;2

Rodier M, Eldin G, Borgne RL (2000) The western boundary of the equatorial pacific upwelling: some consequences of climatic variability on hydrological and planktonic properties. J Oceanogr 56:463-471. https://doi.org/10.1023/A:1011136608053

Ropelewski CF, Halpert MS (1987) Global and regional scale precipitation patterns associated with the El-Nino southern oscillation. Mon Weather Rev 115:1606-1626. https://doi.org/10.1175/15200493(1987)115\%3c1606:Garspp\%3e2.0.Co;2
Ropelewski C, Jones P (1987) An extension of the tahiti-darwin souther oscillation index. Monwearev 115:2161-2165. https://doi.org/10. 1175/1520-0493(1987)115\%3c2161:AEOTTS\%3e2.0.CO;2

Singh A, Delcroix T, Cravatte S (2011) Contrasting the flavors of El Niño-Southern Oscillation using sea surface salinity observations. J Geophys Res-Oceans 116:1-16. https://doi.org/10.1029/2010J C006862

Suarez MJ, Schopf PS (1988) A delayed action oscillator for ENSO. J Atmospheric Sci 45:3283-3287

Takahashi K, Montecinos A, Goubanova K, Dewitte B (2011) ENSO regimes: reinterpreting the canonical and Modoki El Niño. Geophys Res Lett 38:1-5. https://doi.org/10.1029/2011g1047364

Trenberth KE (1984) Signal versus noise in the Southern Oscillation. Mon Weather Rev 112:326-332. https://doi.org/10.1175/15200493(1984)112\%3c0326:Svnits\%3e2.0.Co;2

Trenberth KE, Stepaniak DP (2001) Indices of El Nino evolution. J Clim 14:1697-1701. https://doi.org/10.1175/1520-0442(2001) 014\%3c1697:Lioeno\%3e2.0.Co;2

Trenberth KE, Hurrell JW (1994) Decadal atmosphere-ocean variations in the Pacific Climate dynamics 9:303-319

Vecchi GA, Wittenberg AT (2010) El Nino and our future climate: where do we stand? Wires Clim Change 1:260-270. https://doi. org/10.1002/wcc. 33

Vecchi GA, Soden BJ, Wittenberg AT, Held IM, Leetmaa A, Harrison MJ (2006) Weakening of tropical Pacific atmospheric circulation due to anthropogenic forcing. Nature 441:73-76. https://doi.org/ 10.1038/nature04744

Vincent EM, Lengaigne M, Menkes CE, Jourdain NC, Marchesiello P, Madec G (2011) Interannual variability of the South Pacific Convergence Zone and implications for tropical cyclone genesis. Clim Dyn 36:1881-1896. https://doi.org/10.1007/s00382-009-0716-3

Wang O, Fukumori I, Lee T, Johnson GC (2004) Eastern equatorial Pacific Ocean T-S variations with El Niño. Geophys Res Lett 31:1-4. https://doi.org/10.1029/2003GL019087

Watanabe M, Kug JS, Jin FF, Collins M, Ohba M, Wittenberg AT (2012) Uncertainty in the ENSO amplitude change from the past to the future. Geophys Res Lett 39. https://doi.org/10.1029/2012g 1053305

Weng H, Ashok K, Behera SK, Rao SA, Yamagata T (2007) Impacts of recent El Niño Modoki on dry/wet conditions in the Pacific rim during boreal summer. Clim Dyn 29:113-129. https://doi.org/10. 1007/s00382-007-0234-0

Yang S, Lau K-M, Schopf PS (1999) Sensitivity of the tropical Pacific Ocean to precipitation-induced freshwater. Clim Dyn 15:737-750

Yeh SW, Kug JS, Dewitte B, Kwon MH, Kirtman BP, Jin FF (2009) El Nino in a changing climate. Nature 461:511-U570. https://doi. org/10.1038/nature08316

Yu J-Y, Kao H-Y, Lee T, Kim ST (2011) Subsurface ocean temperature indices for Central-Pacific and Eastern-Pacific types of El Niño and La Niña events. Theor Appl Climatol 103:337-344. https:// doi.org/10.1007/s00704-010-0307-6

Zhang RH, Busalacchi AJ (2005) Interdecadal changes in properties of El Niño in an intermediate coupled model. J Clim 18:1369-1380

Zhang XL, Clarke AJ (2017) On the dynamical relationship between equatorial pacific surface currents, zonally averaged equatorial sea level, and El Nino prediction. J Phys Oceanogr 47:323-337. https://doi.org/10.1175/Jpo-D-16-0193.1

Zhang RH, Rothstein LM, Busalacchi AJ (1998) Origin of upper-ocean warming and El Niño change on decadal time scales in the Tropical Pacific Ocean. Nature 391:879-883

Zhang R-H, Busalacchi AJ (2009) Freshwater Flux (FWF)-Induced Oceanic Feedback in a Hybrid Coupled Model of the Tropical Pacific Journal of Climate 22:853-879 https://doi.org/10.1175/ 2008jcli2543.1 
Zhang MH, Song H (2006) Evidence of deceleration of atmospheric vertical overturning circulation over the tropical Pacific. Geophys Res Lett 33. doi:https://doi.org/10.1029/2006g1025942

Zheng F, Zhang R-H, Zhu J (2014) Effects of interannual salinity variability on the Barrier Layer in the Western-Central equatorial pacific: a diagnostic analysis from Argo. Adv Atmosp Sci 31:532-542. https://doi.org/10.1007/s00376-013-3061-8

Zhi H, Zhang R-H, Lin P, Shi S (2019a) Effects of Salinity Variability on Recent El Niño Events Atmosphere 10:475 doi:https://doi.org/ 10.3390/atmos 10080475

Zhi H, Zhang R-H, Lin P, Yu P (2019b) Interannual Salinity Variability in the Tropical Pacific in CMIP5 Simulations Advances in Atmospheric Sciences 36:378-396 https://doi.org/10.1007/ s00376-018-7309-1

Zhu J et al (2014) Salinity Anomaly as a Trigger for ENSO Events. Sci Rep 4:6821. https://doi.org/10.1038/srep06821

Publisher's Note Springer Nature remains neutral with regard to jurisdictional claims in published maps and institutional affiliations. 